\title{
The Corky Root Rot Pathogen Pyrenochaeta lycopersici Secretes a Proteinaceous Inducer of Cell Death Affecting Host Plants Differentially
}

\author{
Pierre-Henri Clergeot, Herwig Schuler, Ejvind Mørtz, Maja Brus, Simina Vintila, and Sophia Ekengren
}

First, fourth, fifth, and sixth authors: Växtfysiology, Botaniska Institutionen, Stockholms Universitet, Stockholm; second author: Karolinska Institutet, Stockholm; and third author: Alphalyse A/S, Odense, Denmark.

Accepted for publication 22 May 2012.

\begin{abstract}
Clergeot, P.-H., Schuler, H., Mørtz, E., Brus, M., Vintila, S., and Ekengren, S. 2012. The corky root rot pathogen Pyrenochaeta lycopersici secretes a proteinaceous inducer of cell death affecting host plants differentially. Phytopathology 102:878-891.

Pathogenic isolates of Pyrenochaeta lycopersici, the causal agent of corky root rot of tomato, secrete cell death in tomato 1 (CDiT1), a homodimeric protein of $35 \mathrm{kDa}$ inducing cell death after infiltration into the leaf apoplast of tomato. CDiT1 was purified by fast protein liquid chromatography, characterized by mass spectrometry and cDNA cloning. Its activity was confirmed after infiltration of an affinity-purified recombinant fusion of the protein with a $\mathrm{C}$-terminal polyhistidine tag. CDiT1 is

culture, and has a putative ortholog in other pathogenic Pleosporales species producing proteinaceous toxins that contribute to virulence. Infiltration of CDiT1 into leaves of other plants susceptible to $P$. lycopersici revealed that the protein affects them differentially. All varieties of cultivated tomato (Solanum lycopersicum) tested were more sensitive to CDiT1 than those of currant tomato (S. pimpinellifolium). Root infection assays showed that varieties of currant tomato are also significantly less prone to intracellular colonization of their root cells by hyphae of $P$. lycopersici than varieties of cultivated tomato. Therefore, secretion of this novel type of inducer of cell death during penetration of the fungus inside root cells might favor infection of host species that are highly sensitive to this molecule.
\end{abstract} highly expressed during tomato root infection compared with axenic
Pyrenochaeta lycopersici is the filamentous ascomycete responsible for corky root rot (CRR), a debilitating and ubiquitous disease of tomato (31). Infection by this pathogen leads the cortex of mature roots to develop a corky texture with time, and small feeder roots to rot (25). As a result, circulation of water and nutrients is disturbed, causing stunt and important fruit yield reduction (16). Isolates of this fungus are not only pathogenic to several species of the family Solanaceae, including pepper, tobacco, and eggplant, but also to other species of Eudicotyledones, such as cucumber, melon, safflower, and spinach $(17,26$, $34,35,39)$.

Control of CRR is problematic, because all methods available are hindered by either prohibitive cost, adverse effect on the environment, low efficiency, or restrictive conditions of use (11). Resistance breeding still stands as the best compromise between efficiency, flexibility of use, and sustainability. Nevertheless, although sources of partial genetic resistances do exist $(18,21$, 33,40 ), introduction of resistance genes into commercially interesting cultivars of tomato has rarely been implemented, because of tedious, costly, and unreliable procedures of screening (10).

Genetic discoveries made recently in pathogens taxonomically related to $P$. lycopersici are opening promising perspectives of improvement of resistance screening procedures. The genus Pyrenochaeta belongs to order Pleosporales, like several other

Corresponding author: P.-H. Clergeot;

E-mail address: pierre-henri.clergeot@botan.su.se

* The $e$-Xtra logo stands for "electronic extra" and indicates that Figures 3 and 5 appear in color online.

http://dx.doi.org/10.1094/PHYTO-01-12-0004

(C) 2012 The American Phytopathological Society necrotrophic and hemibiotrophic plant pathogens, such as Alternaria, Cochliobolus, Pyrenophora, Phaeosphaeria, Leptosphaeria, Pleospora, Phoma, and Didymella spp. (42). Virulence of these pathogens often depends on their capacity to produce hostselective toxins (HSTs), molecules both promoting infection and determining host specificity (23). Cochliobolus spp. and pathogenic subspecies of Alternaria alternata secrete phytotoxic secondary metabolites required to cause disease on specific genotypes of their hosts (23). The three pathogens of cereals Stagonospora nodorum (anamorph of Phaeosphaeria nodorum, responsible of wheat glume blotch), Pyrenophora tritici-repentis (wheat tan spot), and P. teres (barley net blotch) have been shown to produce proteins contributing to virulence $(14,28)$. Wheat resistance against $S$. nodorum has a complex and polygenic determinism with additive effects (32) and seemed difficult to unravel, until demonstration was made that $S$. nodorum secretes proteinaceous HSTs contributing quantitatively to virulence, and that a gene of sensitivity $(S)$ of wheat is corresponding to each gene encoding an HST of the pathogen (14). Additive effects resulting from several such pairwise genetic interactions determine glume blotch severity, partial resistance of wheat being due to HST-insensitive alleles of $S$ genes, which are usually recessive (13). Because they are major virulence determinants interacting with a limited number of specific host genes that condition resistance, characterization of putative HSTs from phytopathogenic Pleosporales species is a research priority. To our knowledge, occurrence of HSTs has never been investigated in Pyrenochaeta lycopersici or in any other root pathogen.

Secretion of phytotoxic molecules by $P$. lycopersici has been reported but it is still unclear whether or not such compounds could contribute both quantitatively and in a host-specific manner to virulence. Their identification might help at clarifying their role and at unraveling the genetics of resistance against CRR in to- 
mato. Estimation of molecular weight of some active compounds secreted in liquid culture and determination of their heat sensitivity suggest a proteinaceous nature (22). Heat-sensitive macromolecules of 10 to $15 \mathrm{kDa}$ secreted by P. lycopersici have also been shown to cause necrosis specifically in the apical part of the root of tomato (7). Tolerance of tomato seedlings to phytotoxicity of $P$. lycopersici culture filtrates was proposed as a test for selecting cultivars tolerant to CRR, based on a correlation between presence of toxins in fungal culture filtrates, host genotype, and disease severity (12). Preliminary experiments carried out in our laboratory have shown that a heat-sensitive macromolecule present in culture filtrates of several isolates of $P$. lycopersici induces cell death in the mesophyll of tomato leaves. Using this robust assay, we aimed to purify this molecule and to evaluate its contribution to CRR.

\section{MATERIALS AND METHODS}

Plant and fungal material. $P$. lycopersici pathogenic isolate DSM 62931 was purchased from Deutsche Sammlung von Mikroorganismen und Zellkulturen $\mathrm{GmbH}$ (Braunschweig, Germany). Isolates ER824, ER876, and ER931 showing variable virulence levels on the roots of tomato 'Corbarino' (19), were kindly provided by A. Infantino (ISPAVE, Rome). Isolates were routinely cultivated on oatmeal-agar medium as previously described (7). For production of culture filtrates, mycelium was grown for 3 weeks in 500-ml Erlenmeyer flasks containing 100 $\mathrm{ml}$ of MS-20 liquid medium at room temperature $\left(19\right.$ to $\left.23^{\circ} \mathrm{C}\right)$ and without shaking. MS-20 was prepared with research grade sucrose (SERVA electrophoresis GmbH, Heidelberg, Germany) at
$20 \mathrm{~g} / \mathrm{liter}$ and Murashige and Skoog (MS) medium, including Gamborg's B5 vitamins $(15,24)$ (Duchefa Biochemie BV, Haarlem, The Netherlands) at $4.4 \mathrm{~g} /$ liter. After cultivation, the medium was drained through cheesecloth and filtered at $0.45 \mu \mathrm{m}$.

Seed of all plant cultivars used in this study (Table 1) were germinated on moistened filter paper in an incubator at $28^{\circ} \mathrm{C}$. Seedlings were transferred into circular pots (height $=11 \mathrm{~cm}$ and diameter $=13 \mathrm{~cm}$ ) filled with a derivative of Cornell peat-lite mix (150 liters of peat moss, 85 liters of medium to coarse vermiculite, $0.6 \mathrm{~kg}$ of dolomitic limestone, $140 \mathrm{~g}$ of $10-10-15$ fertilizer [NPK rating: $10 \%$ of total weight in elemental $\mathrm{N}, 4.4 \%$ in elemental $\mathrm{P}$, and $12.45 \%$ in elemental $\mathrm{K}]$, and $0.6 \mathrm{~kg}$ of $17-6-12$ fertilizer) immediately after root emergence and cultivated in the greenhouse. Light conditions were 150 to $300 \mu \mathrm{mol}$ photons $\mathrm{m}^{-2} \mathrm{~s}^{-1}$. Temperature was set to $22^{\circ} \mathrm{C}$ during the daily light cycle of $13 \mathrm{~h}$ and to $19^{\circ} \mathrm{C}$ during the daily dark cycle of $11 \mathrm{~h}$. Relative humidity was not regulated.

Leaf infiltration assays. Syringes $(1 \mathrm{ml})$ were used to inject 30 to $100 \mu \mathrm{l}$ of fungal culture filtrate into the apoplast of the first or second leaves of three plants for each species tested. The epidermis of the abaxial side of the leaves was gently pricked with a needle before infiltration. Plants were cultivated in the greenhouse in the conditions described for preparation of plant material. Leaves of all plant cultivars tested at the same time were infiltrated with the same batch of filtrate for comparison. Infiltration of sterile MS-20 medium was used as negative control. Surface of infiltrated area was proportional to the volume of liquid infiltrated and was delimited with a marker immediately after infiltration. Cell death-inducing activity was monitored after 24 to $72 \mathrm{~h}$ of incubation in the greenhouse.

TABLE 1. Plant cultivars used in this study

\begin{tabular}{|c|c|c|}
\hline Species name & Cultivar & Seed provided by or purchased from \\
\hline \multirow{5}{*}{ Solanum lycopersicum } & Money Maker & Department of Plant Pathology, Cornell University, Ithaca, NY \\
\hline & Mogeor & ISPAVE, Rome \\
\hline & Pearson & Department of Plant Pathology, Cornell University, Ithaca, NY \\
\hline & PI 260397 96GI & USDA-ARS, Cornell University, Geneva, NY \\
\hline & Castlemart & Department of Plant Pathology, Cornell University, Ithaca, NY \\
\hline \multirow[t]{3}{*}{ S. pimpinellifolium } & Culebras & TGRC, University of California, Davis \\
\hline & Viv & USDA-ARS, Cornell University, Geneva, NY \\
\hline & Pichilingue & TGRC, University of California, Davis \\
\hline S. lycopersicum $\times S$. habrochaites & F1 Brigeor & INRA, Montfavet, France \\
\hline S. neorickii & $\ldots$ & TGRC, University of California, Davis \\
\hline Nicotiana benthamiana & $\ldots$ & Department of Plant Pathology, Cornell University, Ithaca, NY \\
\hline N. tabaccum & W38 & Botaniska Institutionen, Stockholms Universitet, Sweden \\
\hline Capsicum аппиит & Maor & Department of Plant Pathology, Cornell University, Ithaca, NY \\
\hline \multirow{4}{*}{ S. melongena } & Langada & NAGREF, Thermi, Greece \\
\hline & PA4 & Universidad Politécnica de Valencia, Valencia, Spain \\
\hline & V-S-11 & Universidad Politécnica de Valencia, Valencia, Spain \\
\hline & C-S-16 & Universidad Politécnica de Valencia, Valencia, Spain \\
\hline Datura stramonium & & Bergianska Trädgården, Stockholm, Sweden \\
\hline \multirow{2}{*}{ Cucumis sativus } & Rhensk Druv & Weibulls-Econova Garden AB, Åby, Sweden \\
\hline & F1 Futura & Weibulls-Econova Garden AB, Åby, Sweden \\
\hline Carthamus tinctorius & Orange Grenade & Bröderna Nelsons Frö AB, Tingsryd, Sweden \\
\hline \multirow[t]{5}{*}{ Cucumis melo } & Boule d'Or & INRA, Montfavet, France \\
\hline & Delicious 51 & INRA, Montfavet, France \\
\hline & Doublon & INRA, Montfavet, France \\
\hline & Ginsen Makuwa & INRA, Montfavet, France \\
\hline & $\operatorname{Iran} \mathrm{A}$ & INRA, Montfavet, France \\
\hline
\end{tabular}


Characterization of $\boldsymbol{P}$. lycopersici culture filtrates. Culture filtrates of the four isolates of $P$. lycopersici used in this study (DSM 62931, ER824, ER876, and ER931) were tested for their capacity to induce cell death after infiltration into Solanum lycopersicum 'Money Maker' (MM) leaves. Heat sensitivity of DSM 62931 filtrates was assessed by keeping an aliquot of $4 \mathrm{ml}$ in a boiling water bath for 15 min before infiltration into MM leaves. In order to determine whether induction of cell death by DSM 62931 filtrates could depend on the exposition of MM leaves to the light, plants were kept overnight in the dark before infiltration, and incubated $48 \mathrm{~h}$ longer in the dark after infiltration. Molecular weight of the cell-death-inducing compound present in DSM 629131 filtrates was evaluated by loading 4-ml aliquots into Amicon Ultra 4 centrifugal filter devices with nominal molecular weight limits (NMWL) of 100, 50, 30, and 10 (Millipore, Billerica, MA). Concentrates resulting from ultrafiltration were diluted to their initial volume of $4 \mathrm{ml}$ with fresh and sterile culture medium before infiltration into MM leaves. Filtrates were infiltrated without dilution. When needed, concentration of protein in the solutions infiltrated into the leaves was determined by the method of Bradford (5), using a NanoDrop ND-1000 spectrophotometer (NanoDrop Technologies, Wilmington, DE) and Bio-Rad Protein Assay reagent (Bio-Rad, Hercules, CA).

Purification and characterization of cell death in tomato 1. Purification of the cell death inducer from culture filtrates of DSM 62931 was carried out by fast protein liquid chromatography (FPLC) using a Pharmacia Äkta Prime apparatus (GE Healthcare, Uppsala, Sweden). Cell-death-inducing activity of each chromatography fraction was determined by infiltration into MM leaves after buffer exchange using Econo-Pac 10 DG disposable chromatography columns (Bio-Rad Laboratories AB, Sundbyberg, Sweden) equilibrated with $20 \mathrm{mM}$ Tris, $\mathrm{pH}$ 8.0. Infiltration of the same buffer was used as negative control. For anion exchange chromatography, filtrates were injected in a 1-ml HiTrap Q-sepharose XL column (GE Healthcare) equilibrated in $20 \mathrm{mM}$ Tris, $\mathrm{pH}$ 8.0. Proteins bound to the anion exchanger were eluted with an $\mathrm{NaCl}$ gradient ( 0 to $1.2 \mathrm{M}$ in $10 \mathrm{~min}$ ) at flow rate of $1 \mathrm{ml} / \mathrm{min}$. For size-exclusion chromatography in native conditions, proteins recovered from the anion exchanger were injected in a Pharmacia HiPrep 16/60 Sephacryl S200 HR gel-filtration column (GE Healthcare) equilibrated with $20 \mathrm{mM}$ Tris ( $\mathrm{pH} \mathrm{8.0)}$ and $150 \mathrm{mM} \mathrm{NaCl}$ at a flow rate of $0.5 \mathrm{ml} / \mathrm{min}$. Size-exclusion chromatography under denaturing conditions was carried out in the same column equilibrated with $6 \mathrm{M}$ Guanidine- $\mathrm{HCl}, 20 \mathrm{mM}$ Tris $(\mathrm{pH} 8.0)$, and $150 \mathrm{mM} \mathrm{NaCl}$ at flow rate of $0.3 \mathrm{ml} / \mathrm{min}$. Internal standards used for size-exclusion experiments were Blue Dextran, carbonic anhydrase $(29 \mathrm{kDa})$, and cytochrome c (12.4 kDa) (Sigma-Aldrich GmbH, Buchs, Switzerland). Stock solutions were prepared in appropriate gel-filtration buffer at a concentration of $1 \mathrm{mg} / \mathrm{ml}$ and stored at $4^{\circ} \mathrm{C}$.

Aliquots of the fractions resulting from size-exclusion chromatography and inducing cell death in MM leaves were concentrated 13- to 14-fold using Amicon Ultra 0.5 centrifugal filter devices with a NMWL of 10 . In all, $10 \mu \mathrm{l}$ was analyzed by sodium dodecyl sulfate polyacrylamide gel electrophoresis (SDSPAGE) in Tris-Tricine buffer system (29). The best candidate for the cell death inducer was searched in fractions showing a strong correlation between (i) a peak of UV absorbance on the chromatogram of size exclusion, (ii) the highest residual cell-deathinducing activity after 3- and 10-fold dilutions with $20 \mathrm{mM}$ Tris ( $\mathrm{pH}$ 8.0), and (iii) the presence of a single band after SDS-PAGE.

A protein sample of the best candidate for cell death in tomato 1 (CDiT1) after separation by SDS-PAGE was cut out from the gel with a blade and sent to Alphalyse A/S (Odense, Denmark) for mass spectrometry (MS) analysis. The protein was reduced and alkylated with iodoacetamide, and digested with trypsin (3). Resulting peptides were concentrated using a ZipTip micropurification column (Millipore) and eluted onto an anchorchip target for analysis with an Autoflex III matrix-assisted laser desorption/ionization tandem time-of-flight (MALDI TOF/TOF) instrument (Bruker Daltonik GmbH, Bremen, Germany). The peptide

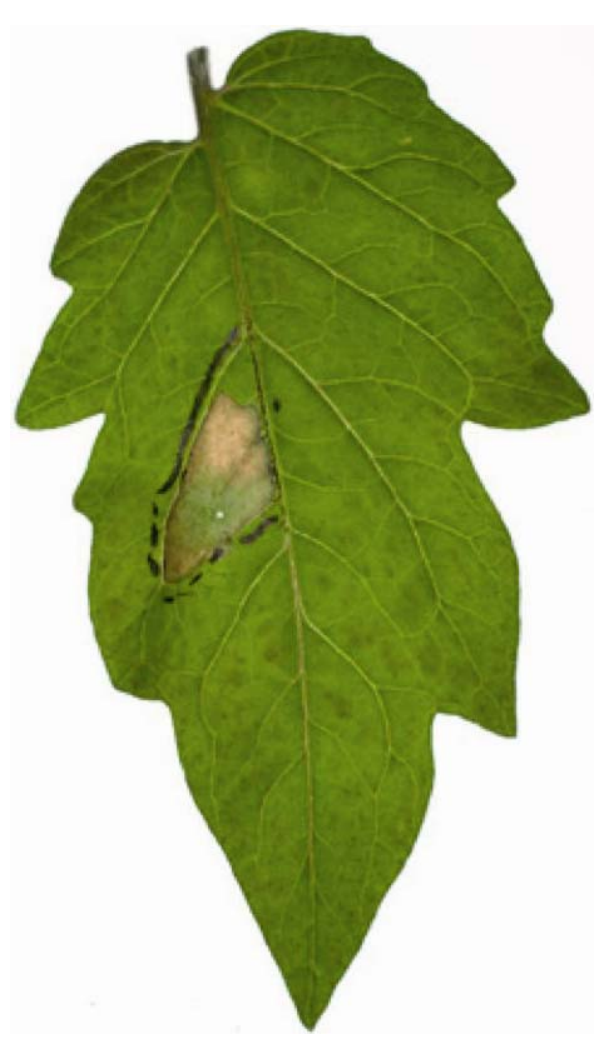

Fig. 1. Typical mesophyll cell death induced after infiltration of an aliquot of a culture filtrate of Pyrenochaeta lycopersici (isolate DMS 62931) into the leaf apoplast of tomato (Solanum lycopersicum 'Money Maker'). Photograph was made $48 \mathrm{~h}$ postinfiltration.

TABLE 2. Primers used in this study

\begin{tabular}{|c|c|}
\hline Name & Sequence \\
\hline $\operatorname{Dg} 7+$ & 5'-GTNACNGGNGTNGCNTC-3' \\
\hline Dg3- & 5'-ACRTCNGCNACRTGRTT-3' \\
\hline Ra5 & 5'-GGAGACTCTCCCTTCGTGAACCACTTAGCCTGGCAG-3' \\
\hline $\operatorname{Ra5n}$ & 5'-GGATCCAGGACGTCCCGAGGGAGTATTGGAGGCCACC-3' \\
\hline Ra3 & 5'-GGTGGCCTCCAATACTCCCTCGGGACGTCCTGGATCC-3’ \\
\hline Ra3n & 5'-CTGCCAGGCTAAGTGGTTCACGAAGGGAGAGTCTCC-3' \\
\hline $\operatorname{Pr} 1+$ & 5'-GCGTGGCCTCCAATACTCCC-3' \\
\hline Pr2- & 5'-CCACGTGATTGAACTTGAGC-3' \\
\hline Hil+ & 5'-CTCCCTCGAGCAATTGACAC-3' \\
\hline Hi2- & 5'-CTACTAGTGATGATGATGATGATGGACCTTCGTAGGAGTAATC-3' \\
\hline Act $1+$ & 5'-ATCAACCCCAAGTCCAACC-3' \\
\hline Act2- & 5'-GGAGCAATGATCTTGACCTTC-3' \\
\hline
\end{tabular}


mixture was analyzed in positive reflector mode for accurate peptide mass determination. Two peptides were selected for further analysis by tandem MS (MS/MS) fragmentation and de novo sequencing using Bruker Biotools software. MS and MS/MS spectra were combined to make a search using Mascot software (www.matrixscience.com) and the Alphalyse A/S in-house protein database, a nonredundant protein sequence database regularly updated with sequence files downloaded from the National Center for Biotechnology Information (NCBI) (http://www.ncbi.nlm. nih.gov/protein). Matching proteins were selected on the basis of their number of matching peptide masses and peptide fragment masses, and identification made according to a probabilityscoring algorithm. Mascot was used for mapping of MALDI MS peptides with CDiT1 sequence as well.

Cloning of CDiT1. Total RNA samples were prepared from mycelium of DSM 62931 cultivated in MS-20 medium during 4 days as described previously (37). First-strand cDNA was synthesized using Superscript III reverse transcriptase (Invitrogen,
Carlsbad, CA), including pretreatment of RNA sample with DNaseI. Initial polymerase chain reaction (PCR) amplification of a fragment of CDiT1 cDNA was performed with degenerated primers designed after translation of the sequences of the two peptides identified after CDiT1 MS analysis, Dg7+ and Dg3(Table 2), and using a touchdown PCR program: annealing temperature was set to decrease at constant rate from 53 to $45^{\circ} \mathrm{C}$ over 40 cycles, and extension time set to $1 \mathrm{~min}$. Amplification products were cloned and analyzed by sequencing. Rapid amplification of cDNA ends (RACE) experiments were performed using SMART RACE cDNA Amplification Kit (Clontech, Mountain View, CA) with primers Ra5 and Ra5n for 5' RACE, and Ra3 and Ra3n (Table 2) for 3' RACE. Reverse-transcription (RT)-PCR amplification of CDiT1 full coding sequence in isolates DMS 62931, ER824, ER876, and ER931 was achieved using primers Fc1+ and Fc2- (Table 2). Orthologs of CDiT1 were searched in NCBI public nucleotide and protein sequence databases (http://www.ncbi.nlm.nih.gov) using BLASTP and BLASTN

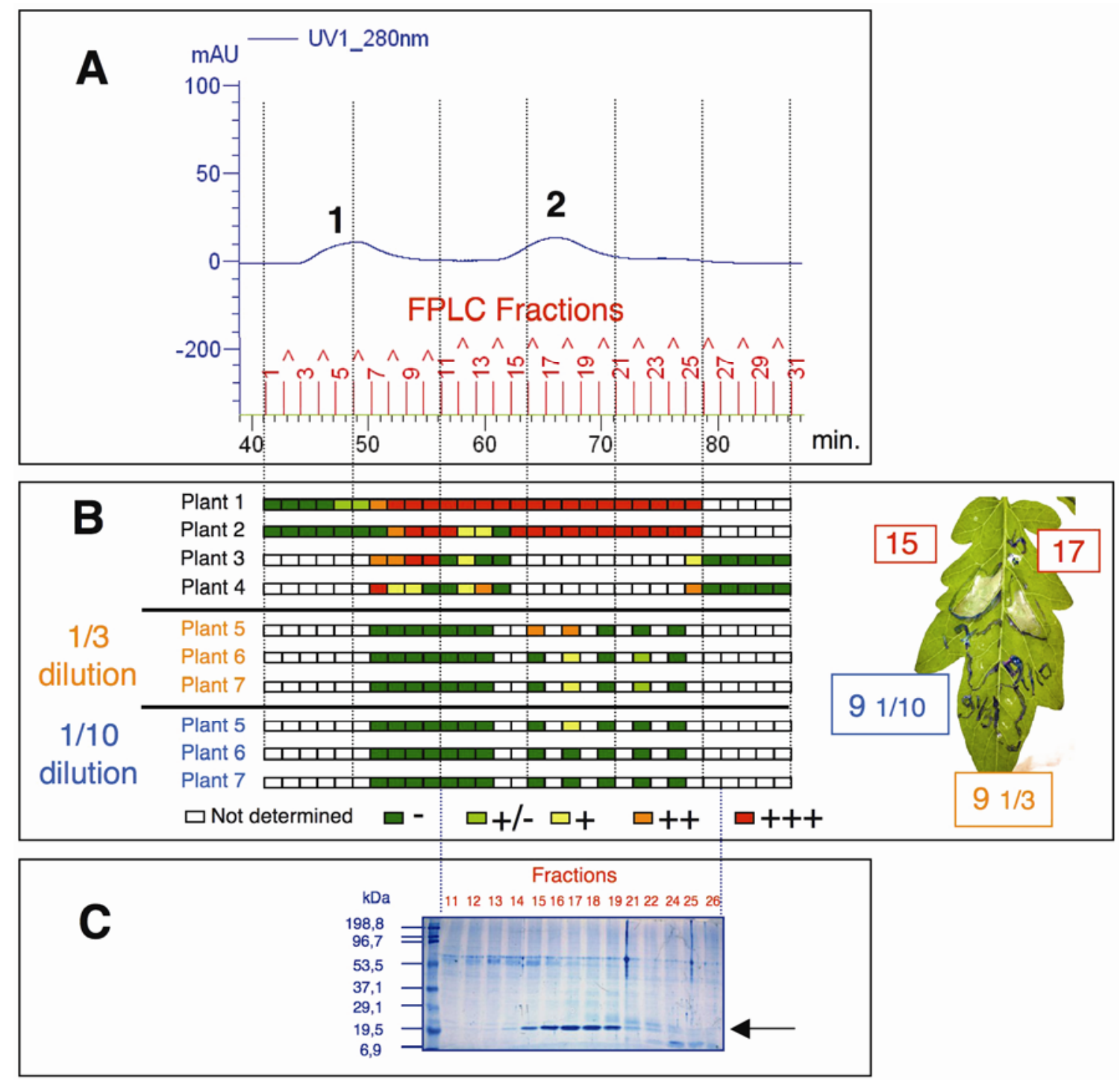

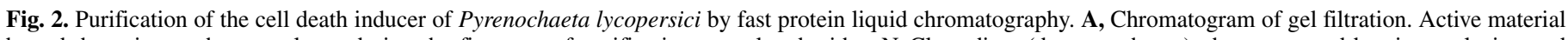

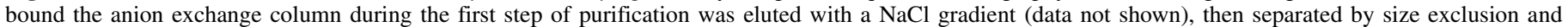

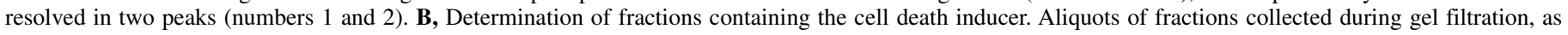

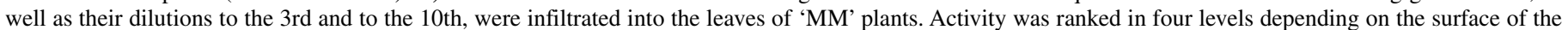

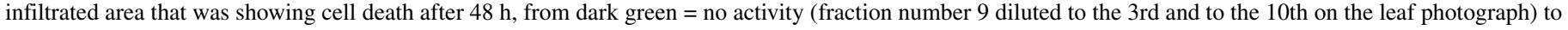

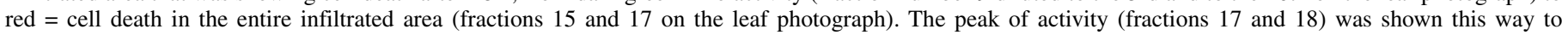

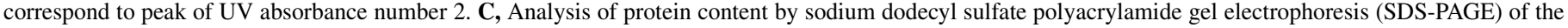

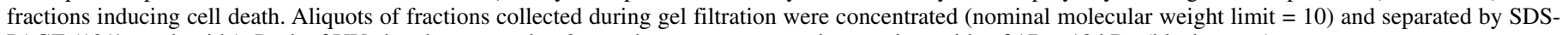
PAGE (12\% acrylamide). Peak of UV absorbance number 2 was shown to correspond to a polypeptide of 17 to $18 \mathrm{kDa}$ (black arrow). 
algorithms (1). Alignment of protein sequences was made using the ClustalW program (36). SignalP 3.0 algorithm (4) was used to detect a putative $\mathrm{N}$-terminal signal peptide for secretion in the amino acid sequence of CDiT1. Putative functional domains were searched using algorithms of protein sequence analysis available at ExPASy (www.expasy.org).

Genomic DNA of $P$. lycopersici was extracted from mycelium of DSM 62931 grown in Iwasaki liquid medium (9) for 7 days. Extraction and Southern blot were performed as previously described (27). Genomic restriction fragments were transferred onto Nylon $\mathrm{N}$ membrane (GE Healthcare) after electrophoresis in a $0.7 \%$ agarose gel. Radioactive probes were synthesized using Amersham Rediprime II Random Prime Labelling System (GE

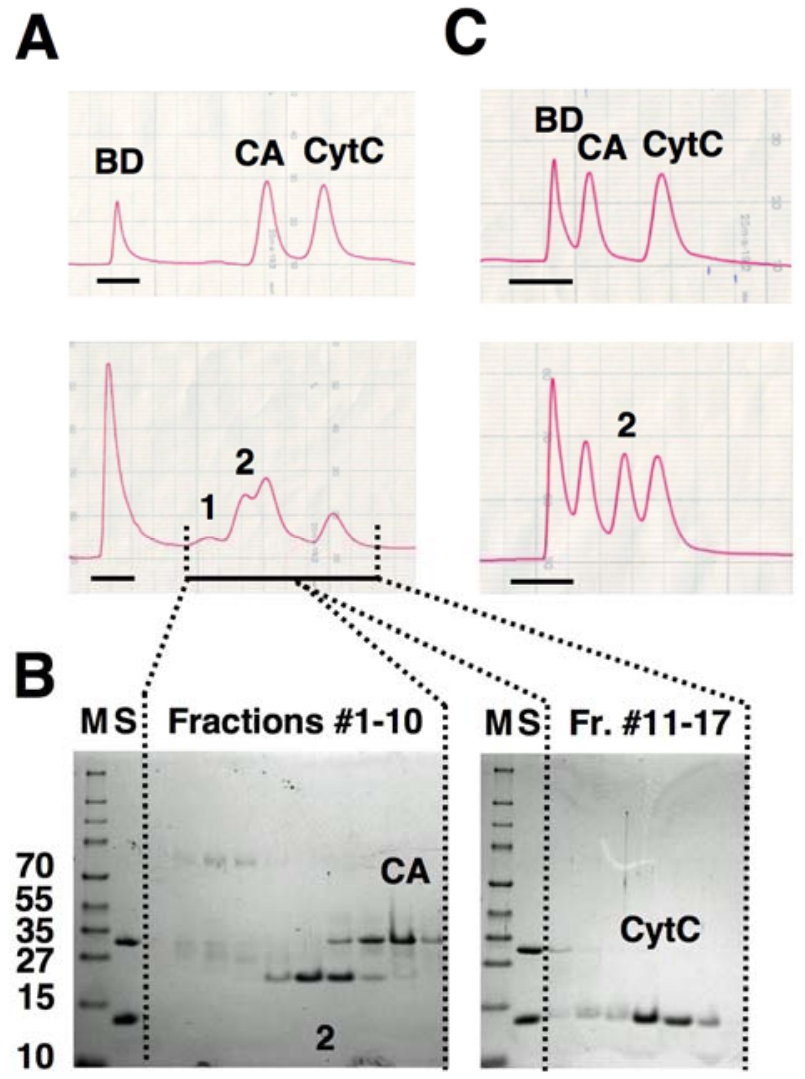

Fig. 3. Cell death in tomato 1 (CDiT1) is a homodimeric protein of $35 \mathrm{kDa}$. $\mathbf{A}$, CDiT1 elutes before carbonic anhydrase during size exclusion in native conditions. Upper chromatogram shows result of a size-exclusion experiment with a mixture of macromolecular standards alone (BD, blue dextran; CA, carbonic anhydrase; CytC, cytochrome c). Lower chromatogram shows separation of a mixture of the standards with the active fraction resulting from anion exchange chromatography of a culture filtrate of Pyrenochaeta lycopersici (isolate DMS 62931). Cell-death-inducing activity was detected in a single peak (number 2), which eluted at the position of a protein of $\approx 35 \mathrm{kDa}$, just before carbonic anhydrase $(29 \mathrm{kDa})$. Flow rate was set at $0.5 \mathrm{ml} / \mathrm{min}$ and paper speed at $1 \mathrm{~mm} / \mathrm{min}$ (black bar: $2 \mathrm{~cm}$ ). B, Sodium dodecyl sulfate polyacrylamide gel electrophoresis (SDS-PAGE) of fractions collected during size exclusion in native conditions. Fractions were concentrated (nominal molecular weight limit $=10$ ) before analysis by SDS-PAGE. Fractions corresponding to peak number 2 showed that CDiT1 ran at molecular mass of $17.4 \mathrm{kDa}$ in SDS-PAGE, lower than carbonic anhydrase. S: protein standards, carbonic anhydrase $(29 \mathrm{kDa})$, and cytochrome c (12.5 kDa). C, CDiT1 elutes between carbonic anhydrase and cytochrome c during size exclusion in denaturing conditions. Upper chromatogram shows separation of a mixture of the protein standards in denaturing conditions. Lower chromatogram shows separation in the same conditions of a mixture of the protein standards with the active fraction resulting from anion exchange chromatography of a culture filtrate of P. lycopersici (isolate DMS 62931). Compared with the same experiment in native conditions, the position of peak number 2 , corresponding to CDiT1, shifted between carbonic anhydrase and cytochrome $\mathrm{c}$, at a position expected for a polypeptide of $17.4 \mathrm{kDa}$. Flow rate was set at $0.3 \mathrm{ml} / \mathrm{min}$ and paper recording at $0.5 \mathrm{~mm} / \mathrm{min}$ (black bar: $2 \mathrm{~cm}$ ).
Healthcare), $\alpha_{-}{ }^{32} \mathrm{P}$ dCTP (Perkin-Elmer, Zaventem, Belgium), and PCR product resulting from CDiTl amplification with primers $\operatorname{Pr} 1+$ and Pr2- (Table 2) as template. For the construction of a genomic mini-library, 5- to 7-kb SpeI-SacI genomic restriction fragments were separated by electrophoresis in a $0.7 \%$ agarose gel and ligated to vector pBluescript SK- (Stratagene, Cedar Creek, TX). Ligation mix was introduced by transformation into competent cells of Escherichia coli XL1-blue strain (Stratagene). In all, 1,008 ampicillin-resistant colonies were transferred onto 82-mm-diameter discs of Nylon $\mathrm{N}$ membrane (GE Healthcare) and screened with a $C D i T 1$ radioactive probe.

Production and purification of recombinant CDiT1 bearing a C-terminal polyhistidine tag (CDiT1::HIS). An expression and transformation vector for the secretion by $P$. lycopersici of a recombinant CDiT1 bearing a C-terminal HIS tag (CDiT1::HIS) was constructed as follows. The 4.4-kb ClaI-SacI genomic restriction fragment containing the CDiTl full genomic sequence (including the two exons, intron, putative promoter, and terminator) was inserted into the polylinker of plasmid pKHyg (39), to give pKWT. The same restriction fragment was inserted into the polylinker of a derivative of plasmid pBluescript SK- (in which the XhoI site of the polylinker had been previously destroyed by ligation to the SalI site), to give pSWT. An oligonucleotide encoding six histidine residues was introduced at the $3^{\prime}$ end of the second exon of CDiTl by PCR amplification using primers Hi1+ and Hi2- (Table 2), Platinum Pfx DNA polymerase (Invitrogen), and the genomic 4.4-kb ClaI-SacI restriction fragment as template. The PCR product was digested with restriction enzymes XhoI and SpeI and inserted into plasmid pSWT, in place of the $0.71-\mathrm{kb} X h o \mathrm{I}-\mathrm{XbaI}$ restriction fragment containing the wild-type sequence of $C D i T 1$, to give pSHIS. Plasmid pSHIS was digested with restriction enzymes $\mathrm{ClaI}$ and $\mathrm{SacI}$, and the 4.4-kb restriction fragment resulting from this double digestion was inserted into the polylinker of plasmid pKHyg, to give pKHIS.

Plasmids pKWT and pKHIS were introduced into the genome of DMS 62931 by protoplast transformation as previously described (7). Ten transformants for each plasmid were grown in $50 \mathrm{ml}$ of MS-20 medium, and aliquots of the culture media were analyzed by SDS-PAGE after 3 weeks of incubation. Recombinant CDiT1::HIS protein was purified using MagneHis Protein Purification System (Promega Corp., Madison, WI). Large-scale purification of CDiT1::HIS was carried out with the filtrate of a culture of transformant KHIS5 in $500 \mathrm{ml}$ of MS-20 medium. Filtrate was concentrated to a volume of $5 \mathrm{ml}$ using Amicon Ultra 15 devices (NMWL 10) before affinity purification using FPLC, with a 1-ml HisTrap HP column (GE Healthcare) equilibrated with $20 \mathrm{mM}$ Tris, $\mathrm{pH}$ 8.0. CDiT1::HIS was eluted with a gradient of imidazole ( 0 to $0.5 \mathrm{M}$ in $30 \mathrm{~min}$ ) at a flow rate of $1 \mathrm{ml} / \mathrm{min}$. Imidazole was eliminated by buffer exchange before infiltration into MM leaves as described for the characterization of FPLC fractions. Aliquots of the elution buffers of both affinity purifycation systems were processed in the same way and used as negative controls for infiltrations into MM leaves.

Root infection assays. Assays were carried out with 12 seedlings of three cultivars of S. lycopersicum (MM, 'Mogeor' and plant introduction [PI] 260397 96GI) and three cultivars of $S$. pimpinellifolium ('Culebras', 'Viv', and 'Pichilingue'). Seedlings were inoculated with mycelium of $1 \mathrm{~K} 4$, a transformant of DSM 62931 carrying a fusion of the $\beta$-glucuronidase (GUS) gene uidA with the promoter of Avr4 of Cladosporium fulvum (20), which is highly expressed during root infection only (7). Seedlings were germinated and inoculated in vitro as described previously (7), except for the following: the inoculum was cut from a mycelium culture of $1 \mathrm{~K} 4$ with a cork borer (diameter $=5 \mathrm{~mm}$ ) and applied directly on the top of the root, mycelium facing the root. Seedlings were incubated for 8 days at room temperature (19 to $23^{\circ} \mathrm{C}$ ). Inoculum was then removed and all roots were stained for GUS expression. Extent of fungal infection was recorded using a 
SMZ-U stereoscopic microscope (Nikon Corporation, Tokyo) as the length $(\mathrm{mm})$ of the root showing a blue staining, indicating expression of GUS. Statistical analysis was carried out using $t$ tests for pairwise comparisons between $S$. lycopersicum and $S$. pimpinellifolium cultivars $(P=0.05)$.
Expression of CDiT1. For the analysis of CDiT1 expression in vitro, total RNA from mycelium of DSM 62931 grown in MS-20 medium were extracted as described (37). For the analysis of CDiT1 expression during infection, 300 MM seedlings were germinated in vitro and inoculated with DSM 62931 as previously

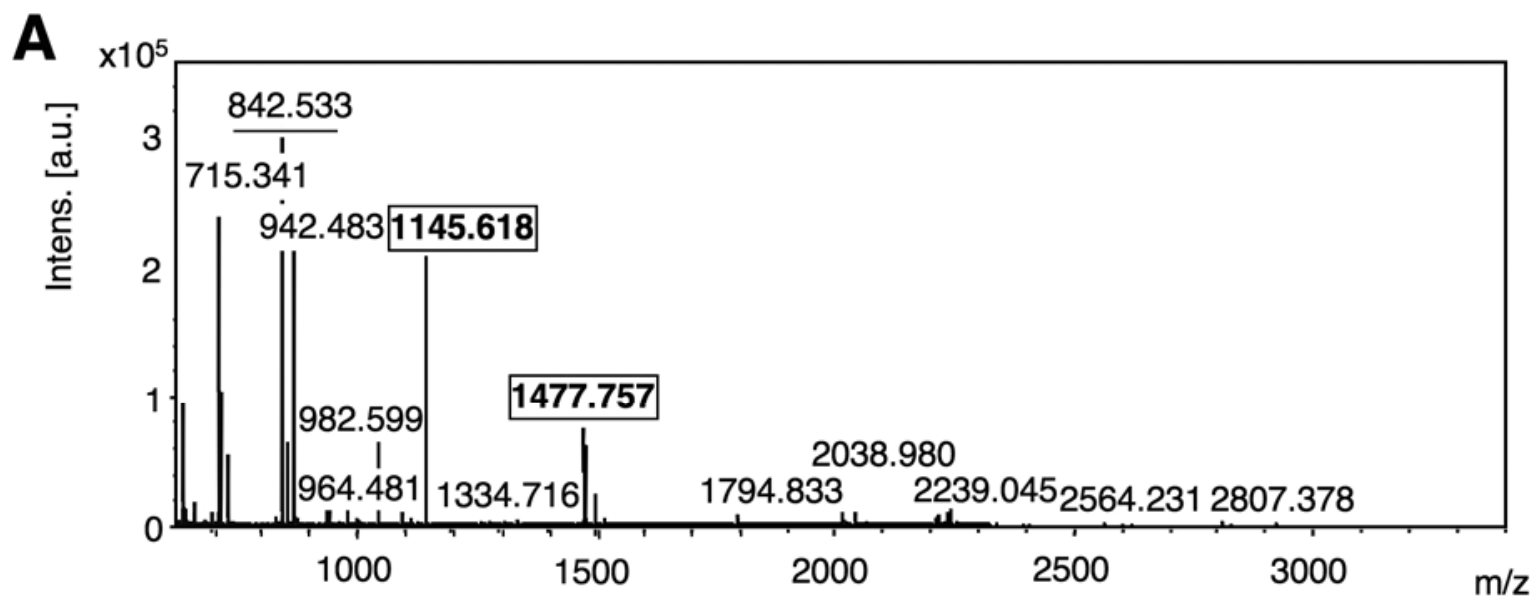

B $\quad$ Mass 1447.8

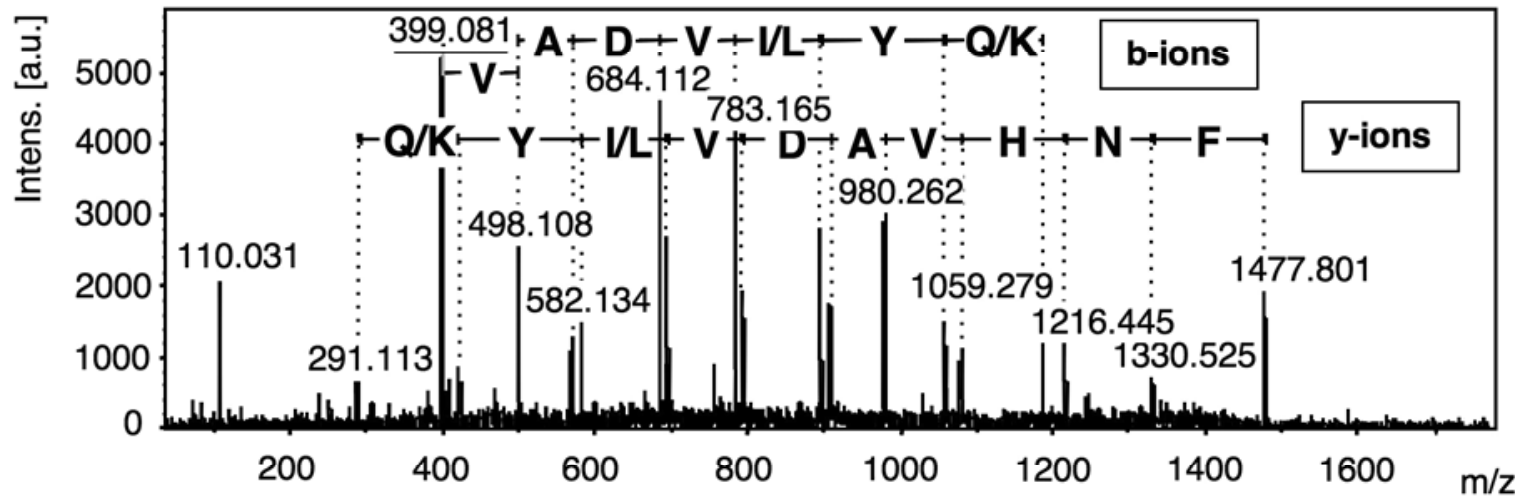

Sequence (partly): F-N-H-V-A-D-V-I/L-Y-Q/K-?

Mass 1145.6

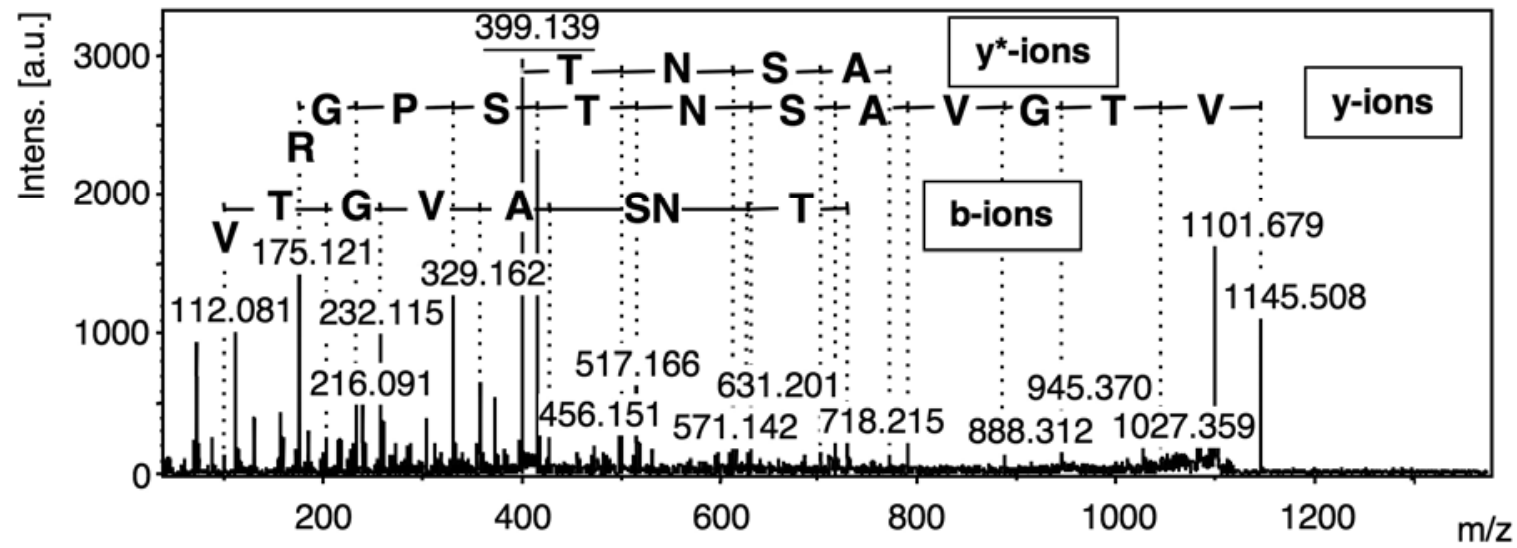

Sequence: V-T-G-V-A-S-N-T-S-P-G-R

Fig. 4. Mass spectrometry (MS) analysis of cell death in tomato 1 (CDiT1). A, Matrix-assisted laser desorption/ionization/MS spectrum of CDiT1. Peptide mixture resulting from reduction and alkylation of CDiT1 with iodoacetamide and digestion with trypsin was analyzed in positive reflector mode for accurate mass determination. Peaks 1145.618 and 1447.757 (boxes) were analyzed by tandem MS (MS/MS). Peak 842.533 (underlined) corresponds to trypsin autolysis fragment. B, MS/MS spectra of two CDiT1 tryptic peptides. Amino acid sequences were deduced after peptide fragmentation using Mascot software. 
TABLE 3. Matrix-assisted laser desorption/ionization/mass spectrometry peptide masses of cell death in tomato 1 (CDiT1)

\begin{tabular}{|c|c|c|c|c|c|}
\hline $\mathrm{m} / \mathrm{z}^{\mathrm{a}}$ & $\mathrm{SN}^{\mathrm{b}}$ & Quality factor & Resolution & Intensity & Area $^{c}$ \\
\hline 634.2 & 347.1 & $\ldots$ & 6,559 & 94,139 & 10,785 \\
\hline 715.341 & 884.1 & $\ldots$ & 6,227 & 239,771 & 33,556 \\
\hline 729.356 & 199.9 & $\ldots$ & 6,993 & 54,218 & 7,085 \\
\hline 811.499 & 3.6 & 58 & 8,089 & $1,155.01$ & 209 \\
\hline 825.518 & 4.3 & 54 & 7,230 & $1,418.17$ & 287 \\
\hline 827.522 & 4.9 & 336 & 3,139 & $1,611.87$ & 860 \\
\hline 832.337 & 19.3 & 685 & 7,492 & $6,358.76$ & 1,288 \\
\hline 842.533 & 972.7 & 67,871 & 6,688 & $320,999.1$ & 75,985 \\
\hline 843.545 & 181.2 & 138 & 13,435 & $59,731.47$ & 6,491 \\
\hline 856.549 & 192.2 & 229,437 & 7,867 & $63,781.38$ & 12,797 \\
\hline 870.564 & 696.5 & 107,834 & 7,507 & $234,749.7$ & 51,413 \\
\hline 882.564 & 3.2 & 55 & 7,797 & $1,074.29$ & 219 \\
\hline 892.544 & 4 & 129 & 7,804 & $1,316.1$ & 266 \\
\hline 919.641 & 6.1 & 456 & 7,916 & $1,839.42$ & 383 \\
\hline 932.509 & 5.2 & 395 & 9,838 & $1,513.77$ & 259 \\
\hline 938.487 & 4.1 & 121 & 10,874 & $1,132.01$ & 194 \\
\hline 942.483 & 44.4 & 30,395 & 8,271 & $12,042.76$ & 2,603 \\
\hline 956.503 & 7 & 688 & 6,221 & $1,795.49$ & 506 \\
\hline 958.475 & 4.6 & 208 & 8,830 & $1,168.24$ & 246 \\
\hline 964.481 & 12.3 & 1016 & 8,407 & $3,031.33$ & 671 \\
\hline 980.482 & 5.6 & 116 & 7,123 & $1,340.69$ & 344 \\
\hline 982.599 & 63.2 & 27,125 & 8,447 & $15,140.68$ & 3,405 \\
\hline 1004.602 & 22.7 & 1811 & 8,525 & $5,358.07$ & 1,212 \\
\hline 1022.641 & 3.8 & 175 & 10,336 &, 870.36 & 164 \\
\hline 1045.591 & 289.1 & 251,589 & 8,583 & $65,145.58$ & 16,276 \\
\hline 1057.595 & 3.9 & 50 & 9,916 &, 879.27 & 188 \\
\hline 1095.683 & 42.2 & 21,033 & 9,670 & $10,865.3$ & 2,602 \\
\hline 1101.592 & 3.8 & 347 & 10,288 & 999.42 & 231 \\
\hline 1109.416 & 6.1 & 745 & 3,342 & $1,625.58$ & 1,148 \\
\hline 1117.687 & 16.2 & 2,270 & 8,437 & $4,426.82$ & 1,206 \\
\hline 1126.581 & 5.8 & 320 & 11,255 & $1,612.63$ & 336 \\
\hline 1127.615 & 4.4 & 296 & 9,929 & $1,252.03$ & 289 \\
\hline 1130.656 & 3.7 & 182 & 4,166 & $1,042.97$ & 607 \\
\hline 1145.618 & 775.4 & 229,340 & 8,576 & $217,306.5$ & 65,290 \\
\hline 1158.642 & 6.2 & 591 & 7,402 & $1,656.17$ & 603 \\
\hline 1167.598 & 5.2 & 133 & 9,740 & $1,349.63$ & 336 \\
\hline 1230.616 & 3.8 & 208 & 12,539 & 757.54 & 179 \\
\hline 1242.889 & 3.8 & 468 & 1,274 & 741.64 & 1,669 \\
\hline 1258.649 & 13.8 & 2,189 & 10,179 & $2,791.91$ & 797 \\
\hline 1277.691 & 18.5 & 3,071 & 11,098 & $3,888.43$ & 1,033 \\
\hline 1291.687 & 3.5 & 128 & 10,179 & 762.81 & 216 \\
\hline 1305.673 & 5.4 & 413 & 11,341 & $1,228.30$ & 348 \\
\hline 1308.62 & 13.3 & 1,826 & 10,430 & $2,937.49$ & 918 \\
\hline 1314.795 & 10 & 2,120 & 10,015 & $2,229.11$ & 697 \\
\hline 1330.637 & 5.3 & 291 & 11,092 & $1,193.92$ & 342 \\
\hline 1334.716 & 27.8 & 11,190 & 10,343 & $6,017.86$ & 1,856 \\
\hline 1348.71 & 5.9 & 520 & 10,047 & $1,242.37$ & 393 \\
\hline 1460.722 & 7.4 & 245 & 10,228 & $1,514.81$ & 566 \\
\hline 1462.663 & 4.5 & 219 & 4,132 & 917.93 & 896 \\
\hline 1477.757 & 361 & 195,998 & 11,848 & $75,670.85$ & 25,820 \\
\hline 1482.731 & 5 & 153 & 10,091 & $1,059.38$ & 389 \\
\hline 1499.759 & 109.2 & 182,404 & 11,634 & $24,507.14$ & 8,422 \\
\hline 1515.726 & 23.3 & 6405 & 11,643 & $5,315.39$ & 1,845 \\
\hline 1517.788 & 4.8 & 406 & 13,346 & $1,102.87$ & 365 \\
\hline 1521.735 & 3.5 & 463 & 13,291 & 827.27 & 242 \\
\hline 1531.685 & 4.3 & 177 & 12,822 & 979.71 & 309 \\
\hline 1537.701 & 4.2 & 272 & 13,092 & 956.67 & 308 \\
\hline 1539.694 & 4.3 & 261 & 10,564 & 953.69 & 398 \\
\hline 1794.833 & 45.5 & 61,583 & 15,222 & $8,349.82$ & 3,185 \\
\hline 1798.833 & 6.4 & 561 & 14,796 & $1,125.50$ & 464 \\
\hline 1810.822 & 3.6 & 112 & 11,933 & 649.37 & 362 \\
\hline 1816.825 & 10.4 & 1508 & 14,904 & $1,866.72$ & 746 \\
\hline 2016.986 & 58.5 & 46,025 & 15,448 & $9,434.66$ & 4,283 \\
\hline 2038.98 & 60.8 & 82,374 & 16,321 & $9,974.88$ & 4,234 \\
\hline 2054.959 & 9.6 & 916 & 14,667 & $1,666.27$ & 793 \\
\hline 2067.058 & 15.5 & 2,262 & 16,130 & $2,611.57$ & 1,136 \\
\hline 2069.081 & 5 & 319 & 13,902 & 857.07 & 429 \\
\hline 2126.091 & 3.4 & 186 & 20,763 & 624.55 & 204 \\
\hline 2211.138 & 26.7 & 8,768 & 17,550 & $4,999.14$ & 2,202 \\
\hline \multirow[t]{2}{*}{2217.052} & 30.9 & 6,577 & 15,986 & $5,693.92$ & 2,844 \\
\hline & & & & & (continued on next page) \\
\hline
\end{tabular}

a Mass over charge.

b Signal to noise ratio.

c Area of $\mathrm{m} / \mathrm{z}$ peak. 
TABLE 3. (continued from preceding page)

\begin{tabular}{|c|c|c|c|c|c|}
\hline $\mathrm{m} / \mathrm{z}^{\mathrm{a}}$ & $\mathrm{SN}^{\mathrm{b}}$ & Quality factor & Resolution & Intensity & Area $^{c}$ \\
\hline 2225.152 & 5.3 & 672 & 17,196 & 985.61 & 419 \\
\hline 2233.118 & 16 & 2,663 & 14,371 & $2,803.70$ & 1,517 \\
\hline 2239.045 & 65.8 & 12,725 & 12,315 & $11,060.29$ & 7,577 \\
\hline 2249.075 & 4.8 & 276 & 8,710 & 794.95 & 822 \\
\hline 2255.027 & 20.6 & 5,302 & 14,173 & $3,283.51$ & 1,907 \\
\hline 2261.135 & 3.7 & 255 & 8,098 & 560.53 & 610 \\
\hline 2271.004 & 4.1 & 267 & 9,079 & 605.21 & 618 \\
\hline 2564.231 & 4.9 & 403 & 20,007 & 398.80 & 193 \\
\hline 2599.357 & 4.5 & 302 & 15,807 & 357.75 & 209 \\
\hline 2807.378 & 45.4 & 4,252 & 13,437 & $2,953.05$ & 2,376 \\
\hline 2921.421 & 5.6 & 488 & 13,789 & 333.58 & 279 \\
\hline
\end{tabular}

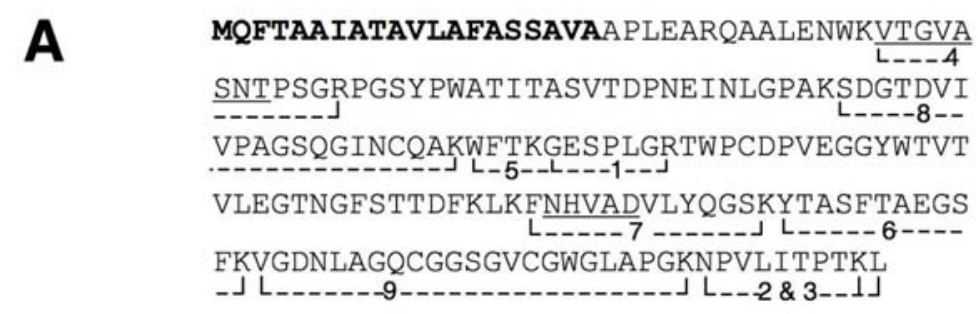

B

Pter

Ptri

CDiT1

Pnod

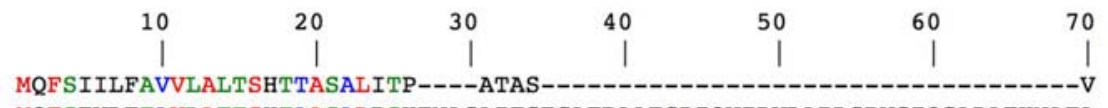

MQFSTVLFTAVLAFTSHTAASALPSHTNASAITSEGAFRAAESDIQVIDVLAPLSPVSIQSADATKNATA

MQFTAAIATAVLAFASSAVAAPLEAR----

MYFATPTIAAVMAFTSFAAATPLQAR--

**: $: * * *:: *: . *:$ * :

Prim.cons. MQFST4LF2AVLAFTSH2AAS2L4ARTNASA22SEGAFRAAESDIQVIDVLAPLSPVSIQSADATKNAT2

Pter
Ptri
CDiT1
Pnod
Prim.cons.

$\begin{array}{rrrrrrr}80 & 90 & 100 & 110 & 120 & 130 & 140\end{array}$ S---QLDNWKVTNVKVQSPSNFPGRYPWATISAKVKDPNRYNLGVG-NNGRSVIVSARKKAVKCEAKINI TGGSQLRNWLVTEVITEEPSDDPGRAPWSVIKAEIKDPNSYDLGIG-GNGRSVTSKARKHSVKCEAKIDT --QAALENWKVTGVASNTPSGRPGSYPWATITASVTDPNEINLGPAKSDGTDVIVPAGSQGINCQAKWFT --QDTLQDWQVTSVNSHTPSGRPGSYPWSSLSANITDPNTINLGTSDSDGTSVIVPAGSQGINCEAKYF-

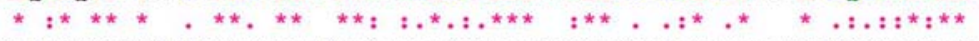

2GQ3QL4NWKVT4V4S4TPSGRPG2YPW2TISA4 22DPN4 2NLG4G2S2G2SVIVPA22QG22CEAKIFT

\section{(1)}
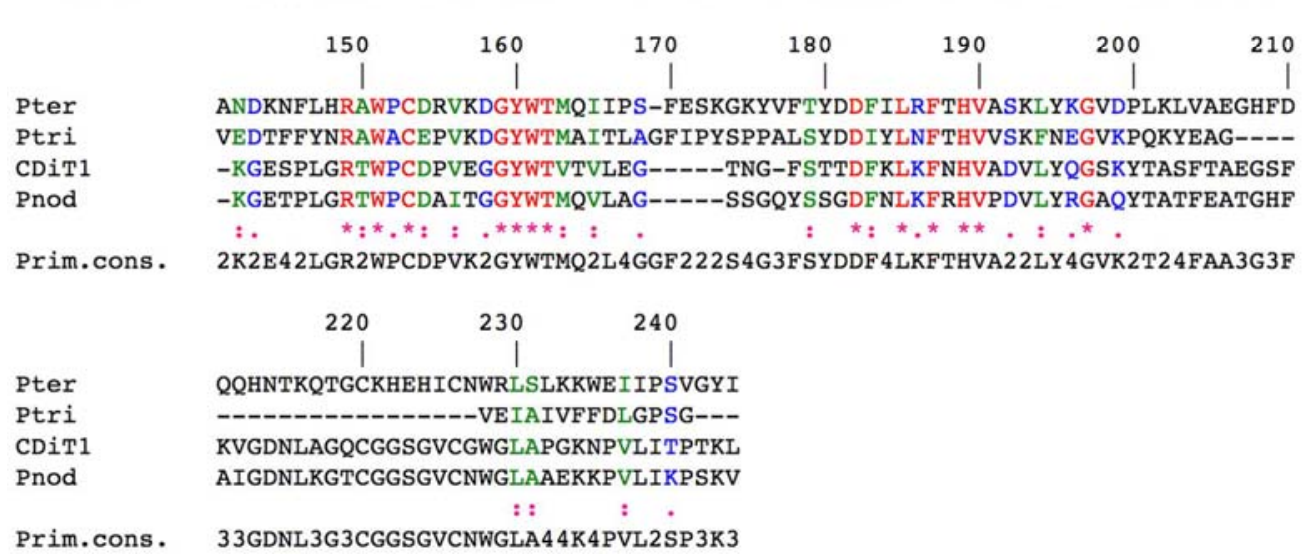

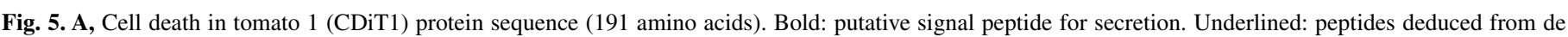

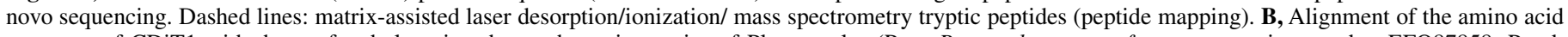

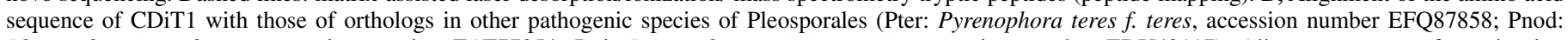

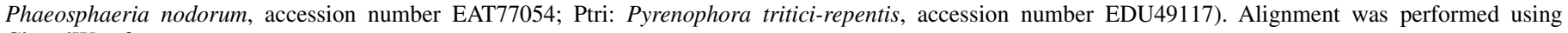
ClustalW software.

described (7). Three days after inoculation, fungal inoculum was removed and a root piece of $1 \mathrm{~cm}$ was cut around the infected area of each seedling. The root pieces were pooled and immediately ground in liquid nitrogen, and total RNA was extracted as previously described (37).
Reverse transcriptions were performed using Superscript III reverse transcriptase in a total volume of $25 \mu$, with $3 \mu \mathrm{g}$ of total RNA. PCR amplification of CDiTl transcripts was carried out using $4 \mu \mathrm{l}$ of cDNA template, primers Pr1+ and Pr2-, annealing temperature of $51^{\circ} \mathrm{C}$, and extension time of $45 \mathrm{~s}$. Amplification of 
fungal actin transcripts was carried out in the same conditions using primers Act1+ and Act2- (Table 2) as a reference gene. To achieve amplification of fungal actin in planta, PCR parameters were modified: nucleotides concentration was raised to $0.3 \mathrm{mM}$, number of cycles was raised to 40, a larger amount of cDNA template was used (7 instead of $4 \mu \mathrm{l}$ ), and Platinum $P f x$ DNA polymerase was used instead of Taq.

\section{RESULTS}

P. lycopersici secretes heat-sensitive macromolecules inducing cell death in tomato leaves. In order to screen molecules secreted by $P$. lycopersici and inducing cell death in tomato $(S$. lycopersicum), the filtrate of a culture of DSM 62931 was

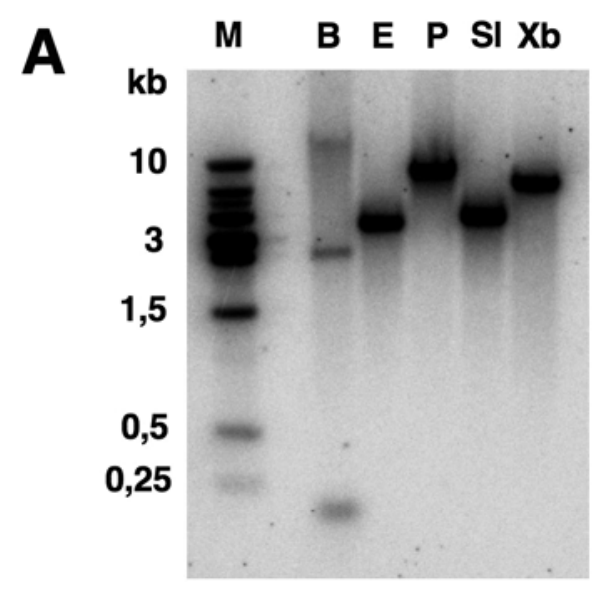

B

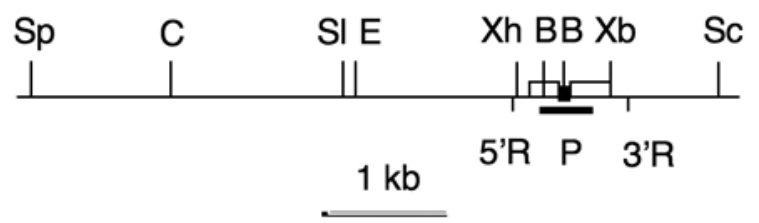

Fig. 6. Southern blot analysis of cell death in tomato 1 (CDiT1). A, Genomic DNA of Pyrenochaeta lycopersici was digested with restriction enzymes BamHI (B), EcoRI (E), PstI (P), SalI (S1), and XbaI (Xb). Restriction fragments were hybridized with a 385 -bp-long $C D i T 1$ radioactive probe $(\mathrm{P})$ at $65^{\circ} \mathrm{C}$. M: molecular weight marker. B, Restriction map of CDiT1 locus. Additional restriction sites: SpeI (Sp), ClaI (C), XhoI (Xh), and SacI (Sc). P: probe used for Southern blot experiment (109 to 494); $5^{\prime} \mathrm{R}: 5^{\prime}$ end of $5^{\prime}$ rapid amplification of cDNA ends (RACE) product (-82); 3'R: $3^{\prime}$ end of $3^{\prime} \mathrm{RACE}$ product (+784). Boxes: CDiT1 exons (exon 1: 1 to 258 and exon 2: 341 to 655). Thick line: $C D i T 1$ intron ( $82 \mathrm{bp})$. infiltrated into the apoplast of leaves of MM. Cell death in MM leaf mesophyll occurred within $24 \mathrm{~h}$ after infiltration. It was characterized by tissue collapse in the entire infiltrated area, which displayed a dry texture and copper color with time (Fig. 1). Three other pathogenic isolates of P. lycopersici (ER824, ER876, and ER931) were also tested. Their culture filtrates were all able to cause cell death in leaves of MM (data not shown). Induction of cell death was not light dependent but was abolished after boiling of the filtrate (data not shown). Molecular mass of the compound responsible for this activity was estimated at 30 to 50 $\mathrm{kDa}$ using centrifugal filter devices (data not shown).

$P$. lycopersici cell death inducer CDiT1 is a homodimeric protein of $35 \mathrm{kDa}$. The inducer of cell death was purified from the filtrate of a culture of DMS 62931 using FPLC with an anion

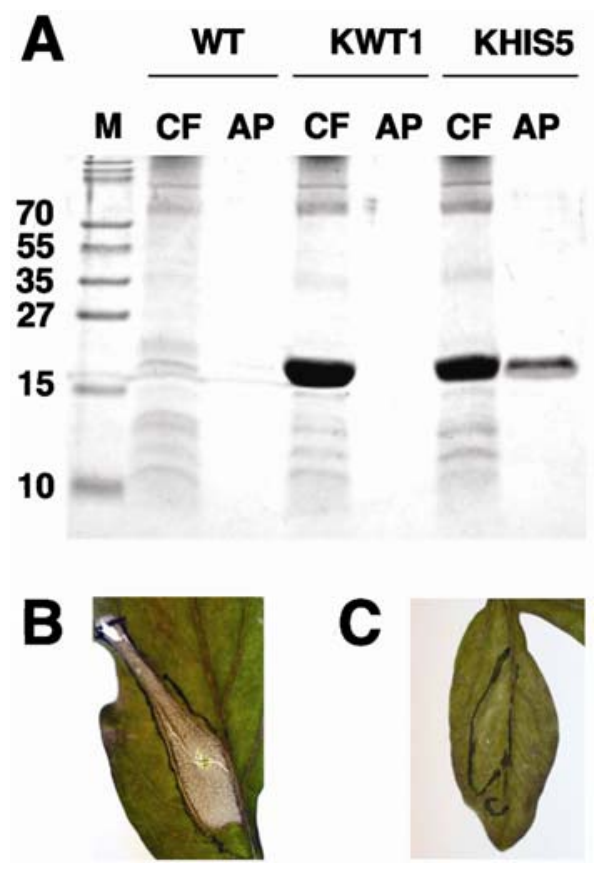

Fig. 7. Recombinant cell death in tomato 1 (CDiT1)::HIS induces cell death in tomato leaves. A, Secretion and purification of CDiT1::HIS from Pyrenochaeta lycopersici transformant KHIS5. Aliquots of crude filtrates (CFs) of cultures of wild type (WT), transformant KWT1, and transformant KHIS5 were concentrated (nominal molecular weight limit $=10$ ). Remaining crude filtrates of WT, KWT1, and KHIS5 cultures were mixed with nickel particles, eluates (AP) concentrated as well, and all types of concentrates analyzed by sodium dodecyl sulfate polyacrylamide gel electrophoresis. Oversecretion of a protein with CDiT1 molecular weight was detected in crude filtrates of KWT1 and KHIS5 cultures (lanes KWT1-CF and KHIS5-CF) but only the eluate of KHIS5 crude filtrate affinity purification contained recombinant CDiT1::HIS (lane KHIS5-AP). B, Infiltration into 'MM' leaf apoplast of the eluate of KHIS5 crude filtrate affinity purification induced cell death of mesophyll cells within 24 h, whereas C, the eluate of KWT1 crude filtrate affinity purification did not.

TABLE 4. Matrix-assisted laser desorption/ionization/mass spectrometry peptide masses of cell death in tomato 1 (CDiT1) used for mapping

\begin{tabular}{|c|c|c|c|c|c|c|}
\hline Peptide number & Input & Found & Deviation & $\begin{array}{l}\text { Missed } \\
\text { cleavage }\end{array}$ & From-to ${ }^{\mathrm{a}}$ & Sequence ${ }^{b}$ \\
\hline 1 & 715.341 & 714.366 & 0.032 & 0 & $76-82$ & GESPLGR \\
\hline 2 & 982.599 & 981.586 & -0.006 & 0 & $162-170$ & NPVLITPTK \\
\hline 3 & $1,095.683$ & $1,094.670$ & -0.006 & 1 & $162-171$ & NPVLITPTKLL \\
\hline 4 & $1,145.618$ & $1,144.584$ & -0.027 & 0 & $15-26$ & VTGVASNTPSGR \\
\hline 5 & $1,277.691$ & $1,276.656$ & -0.027 & 1 & $72-82$ & WFTKGESPLGR \\
\hline 6 & $1,308.620$ & $1,307.603$ & -0.009 & 0 & $127-138$ & YTASFFAEGSFK \\
\hline 7 & $1,477.757$ & $1,476.736$ & -0.014 & 0 & $114-126$ & FNHVADVLYQGSK \\
\hline 8 & $2,016.986$ & $2,015.958$ & -0.020 & 0 & $52-71$ & SDGTDVIVPAGSQGINCQAK \\
\hline 9 & $2,217.052$ & $2,216.010$ & -0.034 & 0 & 139-161 & VGDNLAGQCGGSGVCGWGLAPGK \\
\hline
\end{tabular}

a CDiT1 putative signal peptide was excluded for mapping. Amino acid residues of peptide, from residue number to residue number.

${ }^{\mathrm{b}} \underline{\mathrm{K}}$ indicates missed trypsin cleavage. 
exchange and a gel filtration column, successively (Fig. 2). Activity was detected in fractions corresponding to a fungal protein of $\approx 35 \mathrm{kDa}$ after a size-exclusion experiment including standards with known molecular masses (Fig. 3A, peak 2). However, SDS-PAGE analysis of the fractions collected during this experiment showed that this fungal protein of $35 \mathrm{kDa}$ is running as a single band of 17 to $18 \mathrm{kDa}$ in these conditions of electrophoresis (Fig. 3B). To confirm that the discrepancy between the two estimations of the molecular mass of this protein was not resulting from an SDS-PAGE artifact, the size-exclusion experiment was repeated using the same internal standards but with a denaturing buffer. In these conditions, the fungal protein eluted at the position expected for a protein of 17 to $18 \mathrm{kDa}$ (Fig. $3 \mathrm{C}$, peak 2). This suggests that this protein is a homodimer made of two subunits of 17 to $18 \mathrm{kDa}$ in native conditions. As the putative candidate for the cell death inducer secreted by $P$. lycopersici, this protein was named CDiT1.

CDiT1 has orthologs in other phytopathogenic fungi. To establish identity of CDiT1, a protein sample was analyzed by MS (Fig. 4A; Table 3). MALDI MS peptide mass fingerprinting did not identify any known homolog of CDiT1 in the Alphalyse A/S in-house protein database. However, de novo sequencing of two tryptic peptides after MS/MS fragmentation yielded sufficient sequence information (Fig. 4B) to design degenerated primers that were used for PCR amplification of a 399-bp piece of CDiT1 cDNA. A full open reading frame (ORF) of 573 bp was deduced from sequence assembly of this PCR product with products of $5^{\prime}$ and $3^{\prime}$ RACE experiments. An N-terminal signal peptide was detected in the polypeptide sequence encoded by this ORF, with high probability of cleavage between amino acids 20 and 21 (Fig. $5 \mathrm{~A})$. The predicted mature secreted protein has 171 residues and a theoretical mass of $17.8 \mathrm{kDa}$, close to the estimation of 17 to 18 $\mathrm{kDa}$ made for CDiT1 after SDS-PAGE. Moreover, mapping of MALDI MS tryptic peptides of CDiT1 with the mature protein sequence gave nine hits and residue coverage of 59\% (Table 4; Fig. 5A), confirming that the cDNA cloned corresponded to CDiT1. The nucleotide sequence encoding CDiT1 was registered in the European Nucleotide Archive under accession number HE615138.

A Southern blot experiment showed that CDiT1 is present in only one copy in the P. lycopersici genome (Fig. 6A). Cloning and sequencing of this genomic locus showed that CDiTl has two exons of 258 and $315 \mathrm{bp}$ and one intron of $82 \mathrm{bp}$ (Fig. 6B). The CDiTl full coding sequence was amplified by RT-PCR from mycelium of $P$. lycopersici isolates ER824, ER876, and ER931 grown in liquid medium. Cloning and sequencing of amplification products confirmed that CDiTl is expressed by these isolates as well, and identical in sequence to the one in DMS 62931 (data not shown).

Fungal orthologs of CDiT1 were searched in public sequence databases. This revealed that CDiT1 has one hypothetical ortholog in three plant pathogens belonging to the order Pleosporales

\begin{tabular}{|c|c|c|c|c|c|}
\hline Latin name & Common name & Cultivar/Ecotype & Family & Crude filtrate & Pure CDiT1 \\
\hline Solanum lycopersicum & tomato & Money Maker & Solanaceae & active (1) & active (1) \\
\hline Solanum lycopersicum & tomato & Moboglan & Solanaceae & active (1) & active (1) \\
\hline Solanum lycopersicum & tomato & Pearson & Solanaceae & active (1) & active (1) \\
\hline Solanum lycopersicum & tomato & Mogeor & Solanaceae & active (1) & active (1) \\
\hline Solanum lycopersicum & tomato & Corbarino & Solanaceae & active (1) & active (1) \\
\hline Solanum lycopersicum & tomato & Castlemart & Solanaceae & active (1) & active (1) \\
\hline Solanum lycopersicum & tomato & P.I. 260397 96GI & Solanaceae & active (1) & active (1) \\
\hline S.lycopersicum X S. habrochaites & F1 interspecific hybrid & Brigeor & Solanaceae & active (1) & active (1) \\
\hline Solanum pimpinellifolium & currant tomato & Culebras & Solanaceae & active (2) & non active \\
\hline Solanum pimpinellifolium & currant tomato & Viv & Solanaceae & active (2) & non active \\
\hline Solanum pimpinellifolium & currant tomato & Pichilingue & Solanaceae & active (1) & non active \\
\hline Solanum pimpinellifolium & currant tomato & Chota to El Angel & Solanaceae & active (1) & non active \\
\hline Solanum pimpinellifolium & currant tomato & Babahoyo & Solanaceae & active (1) & non active \\
\hline Solanum neorickii & wild tomato & unknown & Solanaceae & active (1) & active (1) \\
\hline Solanum melongena & eggplant & V-S-11 & Solanaceae & active (2) & non active \\
\hline Solanum melongena & eggplant & PA 4 & Solanaceae & active (2) & non active \\
\hline Solanum melongena & eggplant & C-S-16 & Solanaceae & active (2) & non active \\
\hline Solanum melongena & eggplant & Tsakoniki & Solanaceae & active (2) & non active \\
\hline Solanum melongena & eggplant & Langada & Solanaceae & active (2) & non active \\
\hline Nicotiana tabaccum & tobacco & W38 & Solanaceae & active (2) & non active \\
\hline Nicotiana benthamiana & wild tobacco & unknown & Solanaceae & active (3) & non active \\
\hline Datura stramonium & jimson weed & Bergianska Trädgården 2009 & Solanaceae & active (1) & active (2) \\
\hline Capsicum annuum & sweet pepper & Maor & Solanaceae & active (2) & non active \\
\hline Capsicum annuum & sweet pepper & Thai Hot & Solanaceae & active (2) & non active \\
\hline Capsicum chinese & chili pepper & Pi 159254 & Solanaceae & active (2) & non active \\
\hline Capsicum chinese & chili pepper & Habanero & Solanaceae & active (2) & non active \\
\hline Capsicum frutescens & wild pepper & 2814.6 & Solanaceae & active (2) & non active \\
\hline Carthamus tinctorius & safflower & Orange Grenade & Asteraceae & active (2) & non active \\
\hline Cucumis sativus & cucumber & Rhens Druv & Cucurbitaceae & active (1) & active (1) \\
\hline Cucumis sativus & cucumber & Futura F1 & Cucurbitaceae & active (1) & active (1) \\
\hline Cucumis melo & melon & Stellio F1 & Cucurbitaceae & active (1) & active (1) \\
\hline Cucumis melo & melon & $\operatorname{Iran} \mathrm{A}$ & Cucurbitaceae & active (2) & non active \\
\hline Cucumis melo & melon & Ogon 9 & Cucurbitaceae & active (1) & active (1) \\
\hline Cucumis melo & melon & Boule d'Or 1 & Cucurbitaceae & active (1) & active (1) \\
\hline Cucumis melo & melon & Ginsen Makuwa & Cucurbitaceae & non active & non active \\
\hline Cucumis melo & melon & Doublon & Cucurbitaceae & active (1) & active (1) \\
\hline Cucumis melo & melon & Delicious 51 & Cucurbitaceae & active (1) & active (1) \\
\hline Cucurbita maxima & pumpkin & Kaempmelon & Cucurbitaceae & active (1) & non active \\
\hline Cucurbita pepo & squash & Diamant F1 & Cucurbitaceae & active (1) & non active \\
\hline
\end{tabular}

Fig. 8. Results of the infiltration of a crude filtrate of Pyrenochaeta lycopersici cultivation medium and of a cell death in tomato 1 (CDiT1) solution into the apoplast of the leaves of various host plants. A green background indicates that the infiltration had no effect. Symptoms were otherwise ranked from yellow (mild chlorosis) to red (cell death) according to their intensity. Symptoms were observed in the entire infiltrated area only where "active" is in bold characters. Number in brackets indicates the number of days required for the expression of the symptoms recorded, which did not evolve beyond that stage. Systemic symptoms outside of the infiltrated area (growth inhibition, or even death of immature leaves) were observed in some Cucurbitaceae species after infiltration with the crude filtrate, and are indicated with "active" in yellow characters. 
(Fig. 5B): Phaeosphaeria nodorum (accession number: EAT77054), Pyrenophora teres f. teres (EFQ87858), and P. triticirepentis (EDU49117). CDiT1 has also one more distant ortholog in two other filamentous fungi belonging to the order Sordariales: Neurospora crassa and Chaetomium globosum (data not shown). None of these orthologs of CDiT1 has been isolated yet but their existence has been inferred from genome or cDNA library sequencing. No protein with a sequence similar to CDiT1 was found in any other organism. No known functional domain was identified in the sequence of mature CDiT1.

Recombinant CDiT1 induces cell death in tomato. To confirm that CDiT1 is causing cell death in MM leaves, a secreted recombinant version of CDiT1 bearing a C-terminal polyhistidine tag (CDiT1::HIS) was produced in Pyrenochaeta lycopersici. A DNA fusion encoding CDiT1::HIS was cloned between CDiT1 promoter and terminator (construction pKHIS) and introduced in the genome of DSM 62931 by protoplast transformation. Transformants bearing additional wild-type copies of CDiTl (construc- tion pKWT) were used as controls. Two transformants, KWT1 and KHIS5, were selected for secreting in a large amount a protein having the molecular mass expected for wild-type CDiT1 and for CDiT1::HIS, respectively (Fig. 7A). Affinity purifications were carried out with culture filtrates of the wild type, KWT1, and KHIS5. Analysis of elution products by SDS-PAGE showed that a single protein with the molecular mass expected for CDiT1::HIS was detected in elution product of KHIS5 only (Fig. 7A). All elution products were infiltrated into MM leaves after buffer exchange but only KHIS5 induced cell death (Fig. 7B and C). Concentration of CDiT1::HIS secreted by KHIS5 was measured after affinity purification and buffer exchange. Serial dilutions of this solution and of a solution of wild-type CDiT1 purified by FPLC were prepared after determination of protein concentration and infiltrated into MM leaves. Activities of the wild-type protein and of CDiT1::HIS were not detectable at concentrations lower than $3 \mu \mathrm{g} / \mathrm{ml}$ (data not shown). The elution product of KHIS5 was also analyzed by size-exclusion chroma-
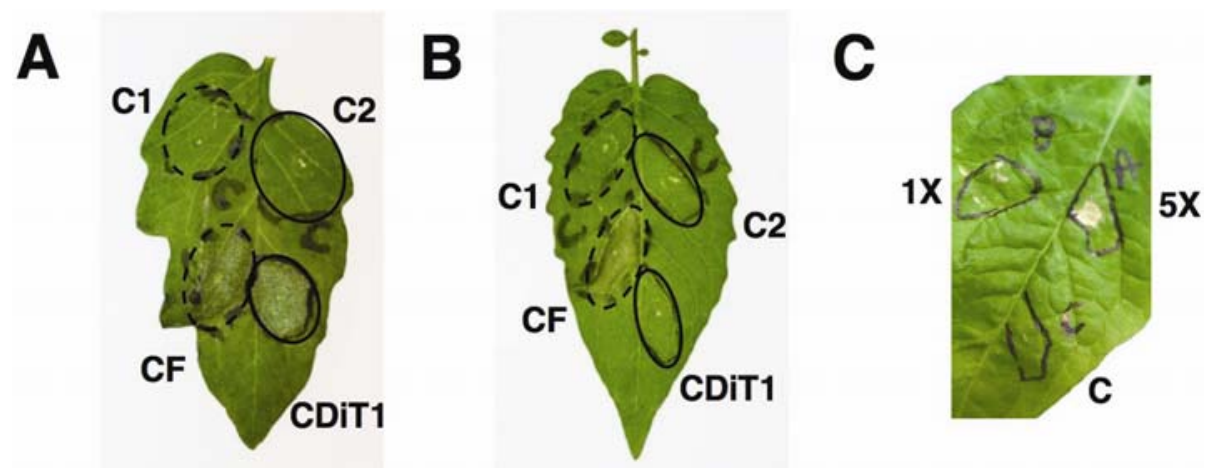

Fig. 9. Currant tomato (Solanum pimpinellifolium) has lower sensitivity to cell death in tomato 1 (CDiT1) than cultivated tomato (S. lycopersicum). A culture filtrate (CF) of Pyrenochaeta lycopersici (isolate DMS 62931) and a solution of CDiT1 purified by fast protein liquid chromatography (FPLC) (CDiT1) were infiltrated into leaves of several cultivars of S. lycopersicum and S. pimpinellifolium. All were sensitive to CF but only cultivars of $S$. lycopersicum were sensitive to CDiT1 (C1: sterile MS-20 medium; C2: sterile solution of $20 \mathrm{mM}$ Tris, $\mathrm{pH}$ 8.0). A, S. lycopersicum 'Pearson'. B, S. pimpinellifolium 'Pichilingue'. C, Solution of wild type CDiT1 purified by FPLC and concentrated five times with a centrifugal filter device $(5 \times)$ can induce cell death in the leaves in $S$. pimpinellifolium Pichilingue (1x: wild-type CDiT1 solution [14 $\mu \mathrm{g} / \mathrm{ml}]$; C: sterile solution of $20 \mathrm{mM}$ Tris, $\mathrm{pH}$ 8.0).
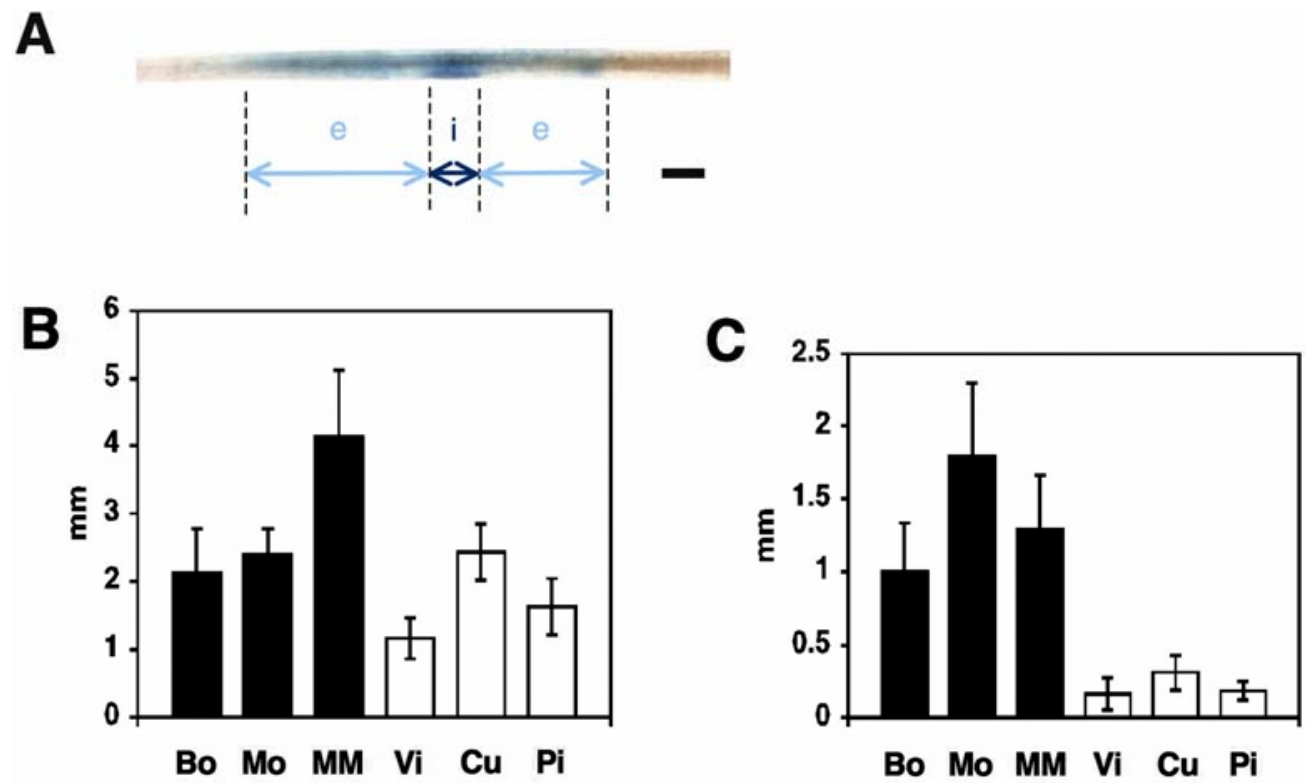

Fig. 10. A, Epicortical (e) and intraradicular (i) expression of $\beta$-glucuronidase (GUS) on the root of an 'MM' seedling infected with Pyrenochaeta lycopersici transformant $1 \mathrm{~K} 4$. Observation was made 8 days post infiltration. Black bar: $1 \mathrm{~mm}$. B, Sensitivity to epicortical root infection by P. lycopersici is not species dependent. Extent of epicortical expression of GUS (mean values \pm standard error) varied with cultivars but did not correlate with the type of Solanum sp. they belong to. Black bars = Solanum lycopersicum cultivars: Bo, 'PI 260397 96GI'; Mo, 'Mogeor'; and MM, 'Money Maker'. White bars = S. pimpinellifolium cultivars: Vi, Viv; $\mathrm{Cu}$, Culebras; and $\mathrm{Pi}$, Pichilingue. C, Cultivars of $S$. pimpinellifolium are more resistant to root cell colonization by $P$. lycopersici than cultivars of S. lycopersicum. Extent of intraradicular expression of GUS (mean values \pm standard error) was significantly lower in three cultivars of S. pimpinellifolium compared with three cultivars of S. lycopersicum. 
tography in native conditions. CDiT1::HIS eluted from the gelfiltration column before carbonic anhydrase, at the retention time corresponding to a protein of $35 \mathrm{kDa}$ (data not shown).

CDiT1 affects host plants of $\boldsymbol{P}$. lycopersici differentially. In order to determine whether other host plants of $P$. lycopersici are also sensitive to CDiT1, the filtrate of a culture of DMS 62931 and a solution of CDiT1 purified by chromatography were infiltrated in the leaf apoplast of several Dicotyledones to which P. lycopersici is pathogenic. Intensity (from a mild chlorosis to complete cell death in the entire infiltrated area) and speed of apparition of symptoms ( 1 to 4 days postinfiltration) following leaf infiltrations with the crude filtrate varied from one species to the other but all of them showed symptoms when compared to control infiltrations of sterile culture medium (Fig. 8). In contrast, infiltration of CDiT1 resulted in cell death in the infiltrated area in some of the plants tested but complete absence of symptoms in others. CDiT1 caused fast cell death in the entire infiltrated area of leaves of seven cultivars of S. lycopersicum (MM, 'Moboglan', 'Pearson' [Fig. 9A, results of infiltrations], Mogeor, Corbarino, 'Castlemart', and PI 260397 96GI), interspecific F1 hybrid S. lycopersicum $\times S$. habrochaites Brigeor, S. neorickii, Datura stramonium, and two cultivars of Cucumis sativus ('Rhensk Druv' and the F1 hybrid 'Futura'). CDiT1 caused cell death in part of the infiltrated area of leaves of four cultivars of $C$. melo highly susceptible to P. lycopersici ('Boule d'Or 51', 'Doublon', 'Ogon 9', and F1 hybrid 'Stellio') but showed no activity in leaves of all other plants tested (S. pimpinellifolium Culebras, 'Chota to El Angel', Viv, 'Babahoyo' and Pichilingue [Fig. 9B, results of infiltrations]; S. melongena 'Tsakoniki', 'Langada', 'PA-4', 'C-S16', and 'V-S-11'; Capsicum annuum 'Maor' and 'Thai Hot'; $C$. chinese 'Habanero' and 'PI 159254'; C. frutescens '2814.6'; Nicotiana tabaccum 'W38'; N. benthamiana; C. tinctorius 'Orange Grenade'; C. pepo F1 hybrid 'Diamant'; Cucurbita. maxima 'Kaempmelon'; and C. melo 'Iran A' and 'Ginsen Makuwa').

In order to determine whether cultivars of $S$. pimpinellifolium are insensitive to CDiT1 or less sensitive than cultivars of $S$. lycopersicum, aliquots of solutions of wild-type CDiT1 purified by FPLC $(14 \mu \mathrm{g} / \mathrm{ml})$ and of recombinant CDiT1::HIS purified by affinity $(11 \mu \mathrm{g} / \mathrm{ml})$ were concentrated fivefold and infiltrated into the leaf apoplast of $S$. pimpinellifolium Pichilingue, Culebras, and Viv and S. lycopersicum MM. Both solutions were active at their two different concentrations in MM. In the three cultivars of $S$. pimpinellifolium, both solutions were inactive at their lowest concentrations but active at their highest (Fig. 9C, results of infiltrations of wild-type CDiT1 in Pichilingue), showing that $S$. pimpinellifolium is also sensitive to CDiT1 but less than $S$. lycopersicum.

Cultivars of $S$. pimpinellifolium are more resistant to root colonization by $P$. lycopersici than cultivars of $S$. lycopersicum. The root of seedlings of three cultivars of $S$. lycopersicum and three cultivars of $S$. pimpinellifolium was inoculated in vitro with $1 \mathrm{~K} 4$, a transformant of $P$. lycopersici carrying a GUS reporter gene fusion that is expressed only during infection. Expression of GUS was monitored after 8 days as a marker of fungal infection.

TABLE 5. Pairwise statistical analysis of the extent of epicortical expression of $\beta$-glucuronidase in three cultivars of Solanum lycopersicum and three cultivars of S. pimpinellifolium

\begin{tabular}{lccc}
\hline & \multicolumn{3}{c}{$P(t$ tests $)$} \\
\cline { 2 - 4 } & \multicolumn{3}{c}{ S. pimpinellifolium } \\
\cline { 2 - 4 } S. lycopersicum & Viv & Culebras & Pichilingue \\
\hline PI 260397 96GI & 0.102 & 0.351 & 0.262 \\
Mogeor & $0.01^{* *}$ & 0.479 & 0.09 \\
Money Maker & $0.009^{* *}$ & 0.076 & $0.021^{*}$ \\
\hline
\end{tabular}

a Asterisks: * indicates $t$ was significant at $P<0.05$ and ** indicates $t$ was very significant at $P<0.01$.
Areas stained in blue were separated in two categories according to their intensity, which reflected a difference in extent of root colonization by the fungus. Epicortical GUS expression was observed as pale blue staining, due to fungal hyphae present at the surface of the root cortex (Fig. 10A, area e). Though clearly distinct from vegetative hyphae, which grow without showing GUS expression, epicortical hyphae were never observed inside root cells at higher magnification. On the contrary, intraradicular GUS expression appeared as intense blue staining, due to fungal hyphae growing deeper inside the root cylinder and invading root cells (Fig. 10A, area i). The six cultivars tested here showed differences in extent of epicortical blue staining after inoculation that depended more on specific properties of each cultivar rather than on the fact that they belonged to $S$. lycopersicum or S. pimpinellifolium species (Fig. 10B; Table 5). In contrast, differences in extent of intraradicular growth of the fungus between the six cultivars were species specific: roots of the three cultivars of $S$. pimpinellifolium tested were all significantly less prone to have their root cells colonized by hyphae of $1 \mathrm{~K} 4$ than those of the three cultivars of S. lycopersicum (Fig. 10C; Table 6). This experiment was performed twice with similar results.

CDiT1 is highly expressed during tomato root infection. Expression levels of CDiT1 during growth of P. lycopersici in vitro and during infection of tomato root were compared using semiquantitative RT-PCR. Expression level of fungal actin was used as reference. Amplification levels of CDiTl cDNA and of actin cDNA in vitro were high and similar. In infected roots, CDiT1 cDNA amplification level was also high, whereas actin cDNA amplification was hardly detectable. The intensity of cDNA amplification signal ratio (CDiTl/actin) was very high, showing clearly that $C D i T 1$ is expressed at a much higher level during infection than during growth in artificial medium (Fig. 11).

\section{DISCUSSION}

The rationale guiding this study was that virulence factors secreted by $P$. lycopersici can be detected after infiltration into host leaves, due to their capacity to induce disease-related symptoms. Hence, our objectives were to purify fungal inducers of cell death and to characterize them by using FPLC, MS, and gene cloning. Here, we report the identification of CDiT1, a novel type of homodimeric protein inducing cell death in tomato. The activity of this protein was confirmed after infiltrating recombinant, affinity-purified CDiT1 into plant leaves. CDiT1 affects host plants of $P$. lycopersici differentially, their sensitivity to the protein being variable. Currant tomato ( $S$. pimpinellifolium) shows lower sensitivity to CDiT1 and higher tolerance to root colonization by $P$. lycopersici compared with cultivated tomato $(S$. lycopersicum). Interestingly, expression of CDiT1 increases drastically during root colonization, when fungal hyphae can secrete the protein directly inside root cells. Together with the ultrastructural modifications observed previously in root cells of a variety of cultivated tomato during fungal penetration (8), our

TABLE 6. Pairwise statistical analysis of the extent of intraradicular expression of $\beta$-glucuronidase in three cultivars of Solanum lycopersicum and three cultivars of $S$. pimpinellifolium

\begin{tabular}{lccc}
\hline & \multicolumn{3}{c}{$P(t$ tests $)$} \\
\cline { 2 - 4 } S. lycopersicum & Viv & Culebras & Pichilingue \\
\cline { 2 - 4 } & $0.0175^{*}$ & $0.038^{*}$ & $0.018^{*}$ \\
PI 260397 96GI & $0.004^{* *}$ & $0.007^{* *}$ & $0.005^{* *}$ \\
Mogeor & $0.006^{* *}$ & $0.013^{* *}$ & $0.006^{* *}$ \\
Money Maker & &
\end{tabular}

a Asterisks: * indicates $t$ was significant at $P<0.05$ and $* *$ indicates $t$ was very significant at $P<0.01$. 
results support the idea that CDiT1 is a virulence factor, effective against sensitive species during this specific stage of infection. Nevertheless, formal demonstration that CDiT1 is a virulence factor is still lacking, because it is not yet possible to perform functional analysis of a gene in P. lycopersici (P.-H. Clergeot, unpublished). The four isolates of $P$. lycopersici monitored in this study secrete an inducer of cell death in liquid culture medium, and their CDiTl transcripts have identical sequences. Therefore, differences in virulence observed among the three isolates (ER824, ER876, and ER931) on Corbarino tomato (19) must be explained by other factors. These three isolates have been collected in the same geographic area (Italy), and a larger survey would be required before concluding that the production of this protein is common to all pathogenic isolates of $P$. lycopersici worldwide. CDiT1 is the first protein of its kind to be characterized and its biochemical function is still unknown; however, other types of dimeric proteins secreted by fungi, such as cerato-platanins, have been shown to play a role as inducers of necrosis during interactions with plants $(38,41)$.

The discovery that CDiT1 has differential activity on various hosts of $P$. lycopersici could contribute to explain the variety of disease symptoms observed on these plants, and outline a model for the molecular interactions between the pathogen and its hosts. Disease caused by $P$. lycopersici on different hosts is not due to different pathogenic subspecies but to different isolates of a single species with a broad host range: isolates pathogenic on tomato are usually virulent on other hosts, and the reverse is also true $(17,35)$. In comparison with other pathogenic species of Pleosporales, there is no evidence that $P$. lycopersici secretes a metabolite required to infect a specific host genotype, ruling out the possibility that virulence could depend on a single major HST, as in Cochliobolus spp. and pathotypes of A. alternata (23). P. lycopersici affects hosts taxonomically more distantly related than those of other pathogenic species of Pleosporales secreting proteinaceous HSTs, such as Stagonospora nodorum or P. triticirepentis $(6,32)$. Therefore, the concept of HST does not seem relevant to describe the interaction between $P$. lycopersici and its hosts. Nevertheless, the picture emerging from published data about host specificity of $P$. lycopersici and severity of CRR $(17,22,26,34,35)$ is that development of disease symptoms could be governed by a limited number of genetic interactions between the pathogen and its different hosts. Reports about host range have sometimes been contradictory, depending on where, with

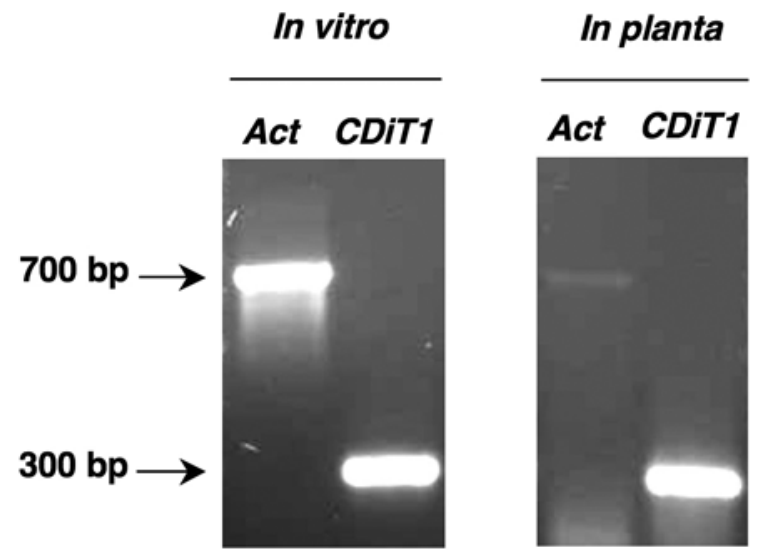

Fig. 11. Expression of cell death in tomato 1 (CDiT1) in Pyrenochaeta lycopersici (isolate DMS 62931). Expressions of CDiT1 and actin (Act) during mycelium growth in liquid medium (in vitro) and during infection of the root of tomato seedlings (in planta) were compared by semiquantitative reversetranscription polymerase chain reaction (PCR). Amplification of both actin and CDiT1 cDNAs was clear in vitro. Amplification of CDiT1 cDNA was strong in planta but amplification of actin was very weak, even after optimization of PCR conditions, showing that the expression level of CDiT1 is much higher during infection than in liquid medium. which fungal isolates, and with which host cultivars infection assays have been made. Cucumber (Cucumis sativus), jimson weed (D. stramonium), and nightshade (Solanum nigrum) have alternatively been described as host or non-host plants $(17,22,35)$. Squash (Cucurbita pepo) has been described as a host plant but one of three cultivars remained symptomless (17). The inoculation of several Solanaceae spp. with an isolate of $P$. lycopersici pathogenic to tomato showed a large range of responses, from complete resistance to a higher sensitivity than tomato, and susceptibility did not always correlate with the possibility of reisolating the fungus from inoculated roots. For example, the fungus could be reisolated from the roots of Physoclaena orientalis, a completely resistant species, whereas it was impossible from the roots of some species described as susceptible, such as pepper $(17,35)$. Reported hosts did not always develop the same type of symptoms, although it was demonstrated that they were caused by Pyrenochaeta lycopersici. Corky roots were observed on tomato, melon (C. melo), and safflower (Carthamus tinctorius) but not on tobacco ( N. tabaccum), pepper (Capsicum annuum), or spinach (Spinacia oleracea), where root browning was observed instead $(17,26,30,34)$. A possible interpretation of these data is that similar disease symptoms occurring on different hosts could be due to the same limited number of virulence factors of $P$. lycopersici, and to similar host $S$ genes, in spite of the taxonomic distance existing between these plants. This would explain why rather distantly related hosts such as tomato and safflower (two Asterid species) and melon (a Rosid species) develop very similar disease symptoms (corky roots), whereas Solanum hirsutum, a wild tomato species fertile with cultivated tomato, is completely resistant. It would also explain why similar intermediate symptoms (root browning) are observed on more distantly related hosts, such as pepper (an Asterid species) and spinach (a Caryophyllale species). In this model, virulence factors of the pathogen affect host plants differentially: symptoms result from the combination of the multiple molecular interactions between the host plant and these factors, and disease severity depends on whether the host is more or less sensitive to each of them. This model establishes a link between host sensitivity to purified fungal molecules detected using laboratory assays and the development of specific disease symptoms. One of our main goals in the future is to test its validity with CDiT1 and with other inducers of cell death secreted by $P$. lycopersici. Response to CDiT1 was characterized by the same clear phenotype of cell death in all cultivars of all highly sensitive host species tested, whereas host species with a lower sensitivity to CDiT1 showed no symptoms. In currant tomato ( $S$. pimpinellifolium), low sensitivity to CDiT1 correlated with a higher tolerance to root colonization by $P$. lycopersici compared with CDiT1-sensitive cultivated tomato. The genetic basis of sensitivity to CDiT1 has not been investigated yet, but the possibility exists, because cultivated tomato and $S$. pimpinellifolium cultivars can be crossed. Moreover, a genetic linkage map between the two species is now available (2), which could facilitate genetic localization.

\section{ACKNOWLEDGMENTS}

This work was supported by the Carl Tryggers foundation for scientific research.

\section{LITERATURE CITED}

1. Altschul, S. F., Madden, T. L., Schäffer, A. A., Zhang, J., Zhang, Z., Miller, W., and Lipman, D.J. 1997. Gapped BLAST and PSI-BLAST: A new generation of protein database search programs. Nucleic Acids Res. 25:3389-402.

2. Ashrafi, H., Kinkade, M., and Foolad, M. R. 2009. A new genetic linkage map of tomato based on a Solanum lycopersicum $\times S$. pimpinellifolium RIL population displaying locations of candidate pathogen response genes. Genome 52:935-956. 
3. Behrendt, N., Jensen, O. N., Engelholm, L. H., Mørtz, E., Mann, M., and Dano, K. 2000. A urokinase receptor-associated protein with specific collagen binding properties. J. Biol. Chem. 275:1993-2002.

4. Bendtsen, J. D., Nielsen, H., von Heijne, G., and Brunak, S. 2004. Improved prediction of signal peptides: SignalP 3.0. J. Mol. Biol. 340:783-795.

5. Bradford, M. M. 1976. A rapid and sensitive method for the quantitation of microgram quantities of protein utilizing the principle of protein-dye binding. Anal. Biochem. 72:248-254.

6. Ciuffetti, L. M., Tuori, R. P., and Gaventa, J. M. 1997. A single gene encodes a selective toxin causal to the development of tan spot of wheat. Plant Cell 9:135-144.

7. Clergeot, P.-H., Rivetti, C., Hamiduzzaman, M. M., and Ekengren, S. 2012. The corky root rot pathogen Pyrenochaeta lycopersici manipulates tomato roots with molecules secreted early during their interaction. Acta Agric. Scand. Sect. B Soil Plant Sci. 62:300-310.

8. Delon, R., Reisinger, O., and Mangenot, F. 1973. Étude aux microscopes photonique et électronique de racines de tomates var. "Marmande" atteintes de maladie liégeuse. Ann. Phytopathol. 5:151-162.

9. Díaz-Perez, S. V., Wayne Crouch, V., and Orbach, M. J. 1996. Construction and characterization of a Magnaporthe grisea bacterial artificial chromosome library. Fungal Genet. Biol. 20:280-288.

10. Doganlar, S., Dodson, J., Gabor, B., Beck-Bunn, T., Crossman, C., and Tanksley, S. D. 1998. Molecular mapping of the $p y-1$ gene for resistance to corky root rot (Pyrenochaeta lycopersici) in tomato. Theor. Appl. Genet. 97:784-788.

11. Ekengren, S. 2008. Cutting the Gordian knot: Taking a stab at corky root rot of tomato. Plant Biotechnol. 25:265-269.

12. Fiume, F., and Fiume, G. 2003. Use of culture filtrates of Pyrenochaeta lycopersici in tests for selecting tolerant varieties of tomato. J. Plant Pathol. 85:131-133.

13. Friesen T. L., Faris, J. D., Solomon, P. S., and Oliver, R. P. 2008. Hostspecific toxins, effectors of necrotrophic pathogenicity. Mol. Microbiol. 10:1421-1428.

14. Friesen, T. L., Meinhardt, S. W., and Faris, J. D. 2007. The Stagonospora nodorum-wheat pathosystem involves multiple proteinaceous host selective toxins and corresponding host sensitivity genes that interact in an inverse gene-for-gene manner. Plant J. 51:681-692.

15. Gamborg, O. L., Miller, R. A., and Ojima, K. 1968. Nutrients requirements of suspension cultures of soybean root cells. Exp. Cell. Res. 50:151-158.

16. Goodenough, P. W., and Maw, G. A. 1973. Effects of Pyrenochaeta lycopersici infection on nutrient uptake by tomato plants. Ann. Appl. Biol. 73:339-347.

17. Grove, G. G., and Campbell, R. N. 1987. Host range and survival in soil of Pyrenochaeta lycopersici. Plant Dis. 71:806-809.

18. Hogenboom, N. G. 1970. Inheritance of resistance to corky root in tomato (Lycopersicon esculentum Mill.). Euphytica 19:413-425.

19. Infantino, A., Aragona, M., Brunetti, A., Lahoz, E., Oliva, A., and PortaPuglia, A. 2003. Molecular and physiological characterization of Italian isolates of Pyrenochaeta lycopersici. Mycol. Res. 107:707-716.

20. Joosten, M. H. A. J., Vogelsang, R., Cozijnsen, T. J., Verbene, M. C., and de Wit, P. J. G. M. 1997. The biotrophic fungus Cladosporium fulvum circumvents $C f$-4-mediated resistance by producing instable AVR4 elicitors. Plant Cell 9:367-379.

21. Laterrot, H. 1983. La lutte génétique contre la maladie des racines liégeuses de la tomate. Rev. Hortic. 238:143-150.

22. Lemaire, J.-M., Glandard, A., Laterrot, H., Conus, M., and Blancard, D. 1984. Mise en évidence d'une toxine chez Pyrenochaeta lycopersici Schneider et Gerlach, agent des racines liégeuses de la tomate et du melon. Rev. Cyt. Biol. Veg. Bot. 7:195-204.

23. Markham, J. E., and Hille, J. 2001. Host-selective toxins as agents of cell death in plant-fungus interactions. Mol. Plant Pathol. 2:229-239.

24. Murashige, T., and Skoog, F. 1962. A revised medium for rapid growth and bioassays with tobacco cultures. Physiol. Plant. 15:473-497.

25. Pohronezny, K. L., and Volin, R. B. 1991. Corky root rot. Pages 12-13 in: "Compendium of Tomato Diseases. American Phytopathological Society, St. Paul, MN.

26. Risser, G., and Laugié, M. 1968. Mise en évidence de la sensibilité de divers cultivars de melon (Cucumis melo L.) à Pyrenochaeta sp., agent de la "maladie des racines liégeuses" de la tomate. Ann. Amelior. Plant. 18:75-80.

27. Sambrook, J., and Russell, D. 2001. Molecular Cloning: A Laboratory Manual, 3rd ed. Cold Spring Harbor Laboratory Press, Cold Spring Harbor, NY.

28. Sarpeleh, A., Wallwork, H., Catcheside, D. E. A., Tate, M. E., and Able, A. J. 2007. Proteinaceous metabolites from Pyrenophora teres contribute to symptom development of barley net blotch. Phytopathology 97:907915.

29. Schägger, H. 2006. Tricine-SDS-PAGE. Nat. Protocols 1:16-21.

30. Schneider, R., and Cruger, G. 1977. Occurrence of the corky root pathogen of tomato (Pyrenochaeta lycopersici) on pepper (Capsicum annuum). Rev. Plant Pathol. 56:5303.

31. Schneider, R., and Gerlach, W. 1966. Pyrenocheata lycopersici nov. spec., der Erreger der Korkwurzhelkrankheit des Tomate. Phytopathol. Z. 56:117-122.

32. Solomon, P. S., Lowe, R. G. T., Tan, K.-C., Waters, O. D. C., and Oliver, R. P. 2006. Pathogen profile-Stagonospora nodorum: Cause of Stagonospora nodorum blotch of wheat. Mol. Plant Pathol. 7:147-156.

33. Szteyn, K. 1962. Interspecific crosses in the genus Lycopersicon I. Backcrosses to Lycopersicon glandulosum. Euphytica 11:149-156.

34. Taylor, J. B., Cole, J. S., Newhook, F. J., and Canter-Visscher, W. 1971. Brown root rot of tobacco caused by Pyrenochaeta lycopersici. N. Z. J. Sci. 14:276-279.

35. Termohlen, I. G. P. 1962. Onderzoekingen over Kurkwortel bij tomaat en over de Kurkwortelschimmel. Tijdschr. Plantenziekten 68:295-367.

36. Thompson, J. D., Higgins, D. J., and Gibson, T. J. 1994. CLUSTAL W: improving the sensitivity of progressive multiple sequence alignment through sequence weighting, position-specific gap penalties and weight matrix choice. Nucleic Acids Res. 22:4673-4680.

37. Vallélian-Bindschedler, L., Mösinger, E., Métreaux, J.-P., and Schweizer, P. 1998. Structure, expression and localization of a germin-like protein in barley (Hordeum vulgare L.) that is insolubilized in stressed leaves. Plant Mol. Biol. 37:297-308.

38. Vargas, W. A., Djonović, S., Sukno, S. A., and Kenerley, C. M. 2008. Dimerization controls the activity of fungal elicitors that triggers systemic resistance in plants. J. Biol. Chem. 283:19804-19815.

39. Viaud, M., Brunet-Simon, A., Brygoo, Y., Pradier, J.-M., and Levis, C. 2003. Cyclophilin A and calcineurin functions investigated by gene inactivation, cyclosporin A inhibition and cDNA arrays approaches in the phytopathogenic fungus Botrytis cinerea. Mol. Microbiol. 50:1451-1465

40. Volin, R. B., and McMillan, R. T. 1977. Inheritance of resistance to Pyrenochaeta lycopersici in tomato. Euphytica 24:75-79.

41. Zaparoli, G., Cabrera O. G., Medrano, F. J., Tiburcio, R., Lacerda, G., and Pereira, G. G. 2009. Identification of a second family of genes in Moniliophthora perniciosa, the causal agent of witches' broom disease in cacao, encoding necrosis-inducing proteins similar to cerato-platanins. Mycol. Res. 113:61-72.

42. Zhang, Y., Schoch, C. L., Fournier, J., Crous, P. W., de Gruyter, J., Woudenberg, J. H. C., Hirayama, K., Tanaka, K., Pointing, S. B., Spatafora, J. W., and Hyde, K. D. 2009. Multi-locus phylogeny of Pleosporales: A taxonomic, ecological and evolutionary re-evaluation. Stud. Mycol. 64:85-102. 